\title{
Optimized photo-stimulation of halorhodopsin for long-term neuronal inhibition
}

Chuanqiang Zhang ${ }^{1,2 \dagger}$, Shang Yang ${ }^{3 \dagger}$, Tom Flossmann ${ }^{1,4 \dagger}$, Shiqiang Gao ${ }^{3}$, Otto W. Witte ${ }^{1}$, Georg Nagel ${ }^{3}$, Knut Holthoff ${ }^{1+}$ and Knut Kirmse ${ }^{1 *+}$ (D)

\begin{abstract}
Background: Optogenetic silencing techniques have expanded the causal understanding of the functions of diverse neuronal cell types in both the healthy and diseased brain. A widely used inhibitory optogenetic actuator is eNpHR3.0, an improved version of the light-driven chloride pump halorhodopsin derived from Natronomonas pharaonis. A major drawback of eNpHR3.0 is related to its pronounced inactivation on a time-scale of seconds, which renders it unsuited for applications that require long-lasting silencing.

Results: Using transgenic mice and Xenopus laevis oocytes expressing an eNpHR3.0-EYFP fusion protein, we here report optimized photo-stimulation techniques that profoundly increase the stability of eNpHR3.0-mediated currents during long-term photo-stimulation. We demonstrate that optimized photo-stimulation enables prolonged hyperpolarization and suppression of action potential discharge on a time-scale of minutes.
\end{abstract}

Conclusions: Collectively, our findings extend the utility of eNpHR3.0 to the long-lasting inhibition of excitable cells, thus facilitating the optogenetic dissection of neural circuits.

Keywords: Halorhodopsin, eNpHR3.0, Optogenetic, Inhibition, Transgenic

\section{Background}

Within a decade, optogenetic tools for reversible silencing of neurons became an integral component of the neuroscientific repertoire. They facilitate analyzing how distinct neuronal populations causally contribute to brain dynamics at the cellular, network, and behavioral level and, in addition, promise substantial therapeutic potential in diverse clinical contexts [1-3]. Optogenetic tools for neuronal inhibition are molecularly diverse, including light-activated chloride channels [4-6], potassium-specific cyclic nucleotide-gated channels fused to a photo-activated adenylyl cyclase [7, 8], G proteincoupled receptors $[9,10]$, and ion pumps $[11-14]$. All actuators developed so far have specific biophysical

\footnotetext{
* Correspondence: knut.kirmse@med.uni-jena.de

${ }^{+}$Chuanqiang Zhang, Shang Yang, and Tom Flossmann contributed equally to this work.

${ }^{\dagger}$ Knut Holthoff and Knut Kirmse jointly supervised this work.

${ }^{1}$ Hans-Berger Department of Neurology, Jena University Hospital, Am

Klinikum 1, 07747 Jena, Germany

Full list of author information is available at the end of the article
}

constraints that are of practical interest when designing and interpreting experimental studies and data, respectively [15]. For example, light-gated chloride channels (e.g., GtACR1) enable divisive inhibition by shunting excitatory currents, but the direction of ion flow entirely depends on the existing electrochemical chloride gradient and, consequently, may also depolarize rather than hyperpolarize cells [16-18]. Light-activated G protein-coupled receptors operate on slower time-scales and modulate canonical signaling cascades that, in addition to reducing excitability, could lead to undesired off-target effects, e.g., changes in gene expression $[19,20]$. In contrast, light-driven ion pumps exhibit on-/off-kinetics in the millisecond range and employ subtractive inhibition, which renders them virtually independent of existing electrochemical gradients [21]. A member of the latter class of actuators is eNpHR3.0 [12], an improved version of the lightdriven chloride pump halorhodopsin derived from Natronomonas pharaonis [11]. Ranking amongst the most widely used inhibitory optogenetic tools, the

(c) The Author(s). 2019 Open Access This article is distributed under the terms of the Creative Commons Attribution 4.0 International License (http://creativecommons.org/licenses/by/4.0/), which permits unrestricted use, distribution, and reproduction in any medium, provided you give appropriate credit to the original author(s) and the source, provide a link to the Creative Commons license, and indicate if changes were made. The Creative Commons Public Domain Dedication waiver (http://creativecommons.org/publicdomain/zero/1.0/) applies to the data made available in this article, unless otherwise stated. 
most critical constraint of eNpHR3.0 results from its prominent inactivation, which refers to a decline in photo-current amplitude during continuous illumination [11, 22-25]. Inactivation has a time constant in the range of seconds implying limited usability of $\mathrm{eNpHR3.0} \mathrm{in} \mathrm{experimental} \mathrm{settings} \mathrm{that} \mathrm{require} \mathrm{long-}$ lasting (>10s) inhibition (for review see [15]). Based on data obtained from structurally related halorhodopsins, inactivation is thought to result from a branched photo-cycle with an accumulation of intermediates containing a deprotonated Schiff base in the 13-cis-retinal configuration [26]. The return to the initial state, which involves thermal reversion to all-trans-retinal, is slow, and few published data suggest that it may be accelerated by blue light $[11,22]$. Using both transgenic mice and Xenopus laevis oocytes, we here systematically explore as to which extent this property could be exploited to increase the temporal stability of eNpHR3.0-mediated photocurrents. We provide and biophysically characterize optimized photo-stimulation protocols that greatly reduce inactivation even for prolonged illumination periods. Our findings thus extend the suitability of eNpHR3.0 to various experimental paradigms, including situations when longlasting inhibition of neuronal activity is required.

\section{Results}

Blue light accelerates the recovery of eNpHR3.0-mediated currents from inactivation in a duration- and powerdependent manner

To explore the potential benefits of alternative eNpHR3.0 photo-stimulation paradigms, we expressed an eNpHR3.0EYFP fusion protein in glutamatergic hippocampal neurons of mice using a transgenic approach $\left(E m \times 1^{\text {IREScre }}\right.$ : eNpHR3.0-EYFP ${ }^{L S L}$ mice) [27]. Whole-cell voltage-clamp recordings from identified $\mathrm{EYFP}^{+} \mathrm{CA} 1$ pyramidal cells were performed in the continuous presence of antagonists of voltage-gated $\mathrm{Na}^{+}$channels $(0.5 \mu \mathrm{M}$ TTX) and ionotropic glutamate and GABA receptors $(10 \mu \mathrm{M}$ DNQX, $50 \mu \mathrm{M}$ APV, $10 \mu \mathrm{M}$ bicuculline) to abolish recurrent excitation and minimize synaptic noise. In agreement with published data, photo-stimulation using yellow light (594 $\mathrm{nm}, 5 \mathrm{~mW}$ at the tip of the optical fiber) induced outward currents that rapidly decayed to $34.2 \pm 3.0 \%$ of the initial peak amplitude within $10 \mathrm{~s}$ of continuous light exposure $\left(I_{\text {peak }} 62.0 \pm 5.8\right.$ pA, $n=15$ cells; Fig. $\left.1 \mathrm{a}, \mathrm{b}\right)$. We probed the recovery from inactivation by an additional $594-\mathrm{nm}$ test pulse at variable time delays $(\Delta t)$ and found that it was slow under control conditions (time constant of a monoexponential fit, $54.1 \pm 2.6 \mathrm{~s}, n=7$ cells; Fig. 1c). Recovery from inactivation was significantly enhanced by a brief pulse of blue light $(488 \mathrm{~nm}, 500 \mathrm{~ms}, 5 \mathrm{~mW})$ in a $\Delta t$ dependent manner [interaction (control/rescue $\times \Delta t$ ): $F=$ 17.8, $\mathrm{df}=4, P=2.9 \times 10^{-9}, n=7 / 8$ cells (control/rescue), mixed-model ANOVA; $\Delta t=15 \mathrm{~s}: t(13)=-12.3, P=1.5 \times$
$10^{-8}, \Delta t=30 \mathrm{~s}: t(8.2)=16.1, P=1.6 \times 10^{-7}, \Delta t=45 \mathrm{~s}:$ $t(13)=-12.3, P=1.6 \times 10^{-8}, \Delta t=60 \mathrm{~s}: t(13)=12.1, P=$ $1.9 \times 10^{-8}, \Delta t=75$ s: $t(13)=-5.1, P=2.1 \times 10^{-4}$, two-sample $t$ tests; Fig. 1b, c]. At the population level, the recovery time constant was not significantly correlated to the degree of inactivation induced by the initial photo-stimulation at $594 \mathrm{~nm}$ (Spearman's rank correlation coefficient $=-0.38, P=0.16, n=15$ cells; Fig. $1 \mathrm{~d}$ ). We next addressed the time and power requirements of blue-light rescue stimulation. In a first set of experiments, we systematically varied the duration of the 488-nm light pulse while keeping the applied power constant $(5 \mathrm{~mW})$. We found that the recovery from inactivation monotonically increased with increasing duration of the blue-light pulse $(F=575, \mathrm{df}=3.2, P=$ $3.4 \times 10^{-28}, n=11$ cells, one-way repeated-measures ANOVA, Huynh-Feldt correction; Fig. 1e, f). In a second set of experiments, we systematically varied the power of the 488-nm light pulse at a constant duration of 1 s. The recovery from inactivation significantly depended on the power of blue light $\left(F=529, \mathrm{df}=7, P=2.3 \times 10^{-62}, n=\right.$ 12 cells, one-way repeated-measures ANOVA; Fig. 1g, h), but saturated at close to $3 \mathrm{~mW}$.

Collectively, our data demonstrate that blue light accelerates the recovery of eNpHR3.0-mediated currents from inactivation in a duration- and power-dependent manner.

\section{Blue light attenuates the inactivation of eNpHR3.0- mediated currents during prolonged photo-stimulation in a mean power-dependent manner}

We next assessed whether blue light may be similarly used to prevent the inactivation of eNpHR3.0-mediated currents when co-applied with photo-stimulation at $594 \mathrm{~nm}$. To this end, we photo-stimulated cells with a constant power of 594-nm light $(5 \mathrm{~mW})$ and systematically varied the power of 488-nm excitation (Fig. 2a, b). We quantified this effect by determining the remaining current at the end of photo-stimulation $\left(I_{\text {late }}\right)$ as a fraction of the peak eNpHR3.0-mediated current (i.e., $\left.I_{\text {late }} / I_{\text {peak }}\right)$. We found that $I_{\text {late }} / I_{\text {peak }}$ strongly depended on the power of blue light $\left(F=226, \mathrm{df}=3.7, P=3.1 \times 10^{-15}, n=6\right.$ cells, one-way repeated-measures ANOVA, Huynh-Feldt correction; Fig. 2b) reaching an apparent saturation at about $3 \mathrm{~mW}$.

We further explored the possibility to minimize the total power of blue light delivered by employing a highfrequency ("pulsed," $1 \mathrm{kHz}$ ) stimulation with a $20 / 80 \%$ (on/off) duty cycle by means of an acousto-optic tunable filter (see the "Methods" section). In a first set of experiments, we compared the effects of continuous versus pulsed photo-stimulation at a constant mean power of either $3 \mathrm{~mW}$ (Fig. 2c, top) or $0.2 \mathrm{~mW}$ by compensatorily increasing the peak 488-nm light power in pulsed stimulation trials. At both power levels, normalized $I_{\text {late }}$ 


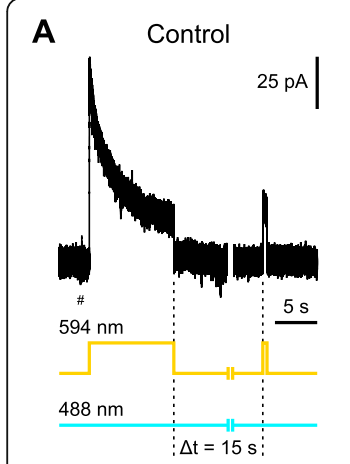

E
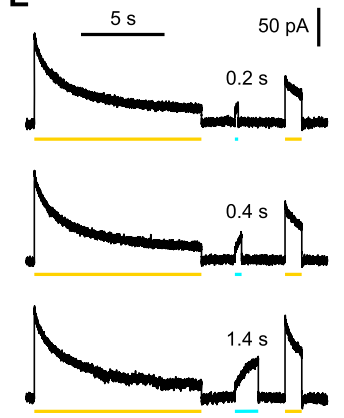

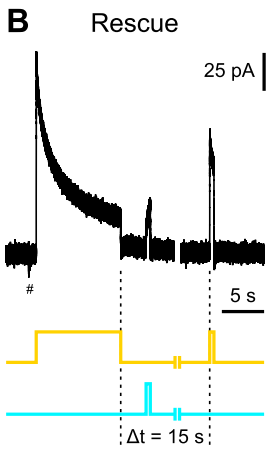

F

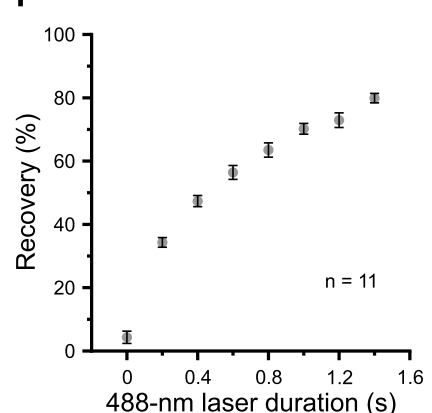

C

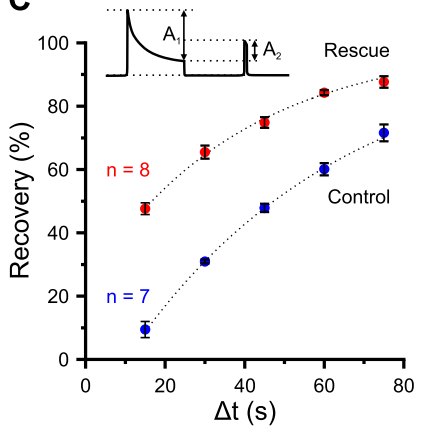

G
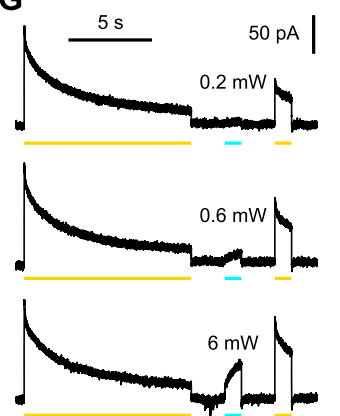

D

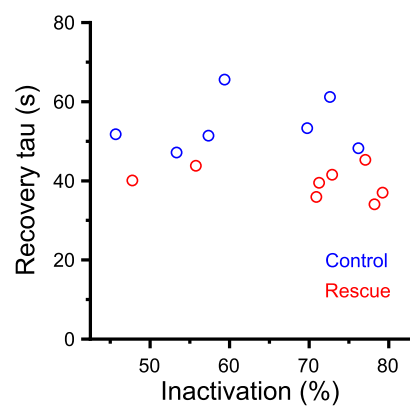

H

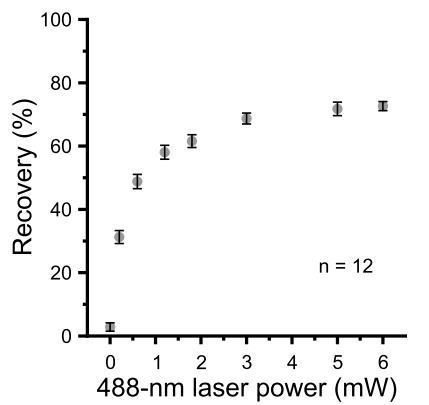

Fig. 1 Blue light accelerates the recovery of eNpHR3.0-mediated currents from inactivation in a duration- and power-dependent manner. a Sample voltage-clamp recording illustrating that prolonged (10 s) photo-stimulation at $594 \mathrm{~nm}(5 \mathrm{~mW})$ induces pronounced inactivation of eNpHR3.0-mediated currents. Note that the recovery from inactivation is slow (test pulse at $\Delta t=15 \mathrm{~s}$ ). $\mathbf{b}$ Sample trace from another cell demonstrating that blue light $(500 \mathrm{~ms}, 488 \mathrm{~nm}, 5 \mathrm{~mW}$ ) accelerates the recovery from inactivation. Also note the outward current induced by blue light. c Recovery of eNpHR3.0-mediated currents is enhanced by blue light. Inset, recovery is defined as the ratio of current amplitudes induced by the test (at $\Delta t$ ) versus initial pulse, measured relative to / late (i.e., recovery $=A_{2} / A_{1}$ ). Dotted lines represent mono-exponential fits to population data. Each cell was tested for all values of $\Delta t$ either without (Control, $n=7$ cells) or with (Rescue, $n=8$ cells) an intervening photo-stimulation at $488 \mathrm{~nm}(500 \mathrm{~ms})$. In $\mathbf{a}$ and $\mathbf{b}$, current responses to - 10-mV voltage steps used to monitor access resistance are clipped for clarity (\#). $\mathbf{d}$ Independent of the degree of inactivation $\left(1-l_{\text {late }} / /_{\text {peak }}\right)$, time constants of recovery are lower for rescue as compared to control trials. Each symbol represents a single cell. e Recovery from inactivation depends on the duration of the 488-nm rescue pulse (blue lines). All traces are from a single cell. $\mathbf{f}$ Quantification. $\mathbf{g}$ Recovery from inactivation depends on the power of the 488-nm rescue pulse at a constant duration of $1 \mathrm{~s}$. All traces are from a single cell. $\mathbf{h}$ Quantification. Data are presented as mean \pm SEM

amplitudes during pulsed stimulation did not significantly differ from those obtained during continuous stimulation $(0.2 \mathrm{~mW}: 100.7 \pm 2.1 \%$ of control, $t(4)=-$ 0.63, $P=0.56, n=5$ cells, paired $t$ test; $3 \mathrm{~mW}: 102.6 \pm$ $1.4 \%$ of control, $t(3)=-1.98, P=0.14, n=4$ cells, paired $t$ test; Fig. 2d). In an independent set of experiments, continuous and pulsed photo-stimulation were compared at a constant peak 488-nm light power of either 3 $\mathrm{mW}$ (Fig. 2c, bottom) or $0.2 \mathrm{~mW}$, which effectively reduced the mean power in pulsed stimulation trials to $20 \%$. In line with the above data, pulsed stimulation at constant peak power was significantly less effective in preventing inactivation as compared to continuous excitation, reflected in lower values of $I_{\text {late }}(0.2 \mathrm{~mW}: 63.5 \pm$ $4.0 \%$ of control, $t(4)=7.11, P=2.1 \times 10^{-3}, n=5$ cells, paired $t$ test; $3 \mathrm{~mW}: 66.9 \pm 5.7 \%$ of control, $t(3)=7.14$, $P=5.7 \times 10^{-3}, n=4$ cells, paired $t$ test; Fig. $2 \mathrm{~d}$ ).

Based on the same rationale and taking into consideration that the deactivation kinetics of eNpHR3.0-mediated currents is in the range of several milliseconds, we next investigated a potential benefit of pulsed $[1 \mathrm{kHz}, 20 / 80 \%$ (on/off) duty cycle] versus continuous photo-stimulation at $594 \mathrm{~nm}$ on the background of a continuous, constantpower $(5 \mathrm{~mW})$ blue-light excitation. We found that $I_{\text {late }}$ amplitudes did not significantly differ between the two regimes if the mean 594-nm light power was kept constant at $3 \mathrm{~mW}$ by compensatorily increasing the peak power in pulsed stimulation trials (normalized $I_{\text {late }} 96.0 \pm 1.6 \%$ ). In contrast, $I_{\text {late }}$ was significantly reduced to $81.4 \pm 1.1 \%$ if the peak 594-nm light power was unchanged (continuous/ mean power $=3 \mathrm{~mW}$ vs. pulsed $/$ mean power $=3 \mathrm{~mW}: P=$ 0.21 , continuous $/$ mean power $=3 \mathrm{~mW}$ vs. pulsed $/$ mean power $=0.6 \mathrm{~mW}: P=7.4 \times 10^{-4}$, post hoc $t$ tests with Bonferroni correction; $F=46.1, \mathrm{df}=2, P=2.3 \times 10^{-6}, n=7$ cells, one-way repeated-measures ANOVA).

We further examined whether the effect of blue light reflects an inherent property of eNpHR3.0 by performing additional experiments on somatostatin-expressing (SOM) 
A

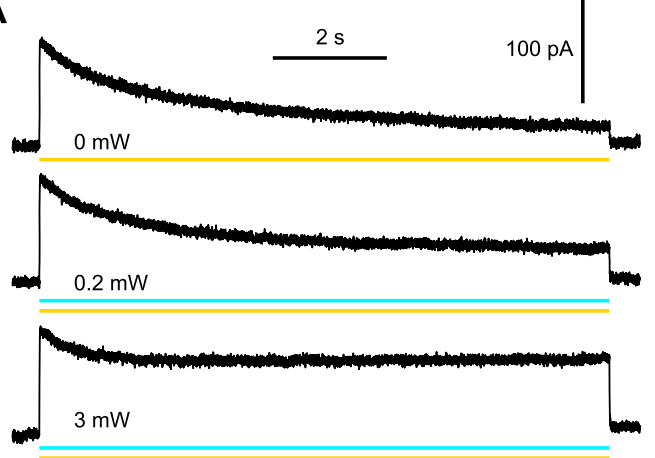

C

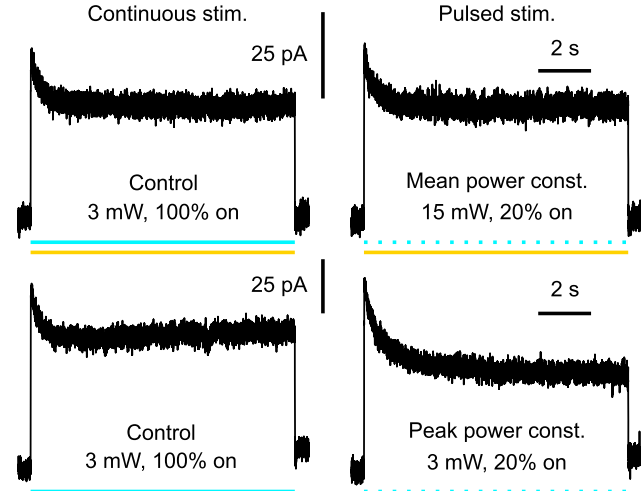

B

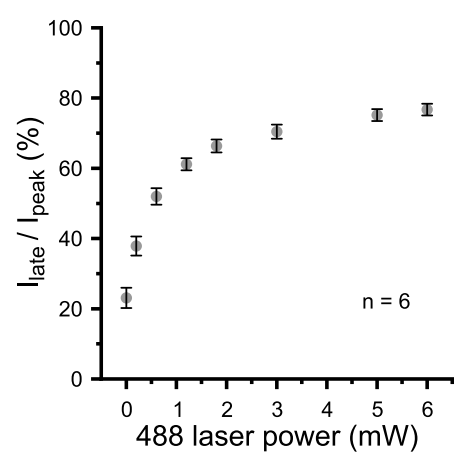

D

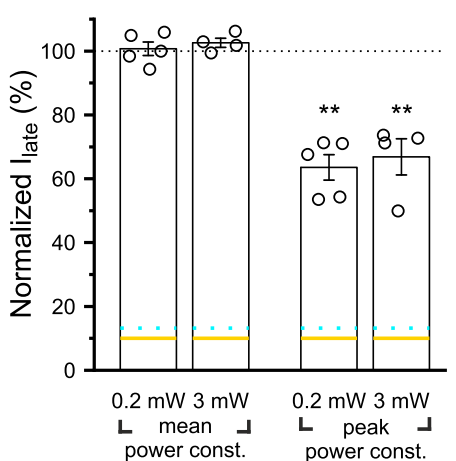

Fig. 2 Co-stimulation at $594 \mathrm{~nm}$ and $488 \mathrm{~nm}$ attenuates the inactivation of eNpHR3.0-mediated currents during prolonged photo-stimulation in a mean power-dependent manner. a Sample voltage-clamp recording from a single cell illustrating eNpHR3.0-mediated currents in response to photo-stimulation at $594 \mathrm{~nm}(5 \mathrm{~mW})$ alone (top) or in combination with $488 \mathrm{~nm}$ at variable power levels (middle and bottom). Power levels indicated refer to 488-nm light. b Dependence of inactivation on the power of 488-nm light. c The rescue effect of 488-nm light on the inactivation of eNpHR3.0-dependent currents depends on its mean, rather than peak, power. Top: continuous 488-nm stimulation (left) is equally effective in attenuating inactivation as compared to pulsed ( $1 \mathrm{kHz}, 20 / 80 \%$ on/off) stimulation at constant mean power (right). Bottom: continuous 488-nm stimulation (left) is more effective in attenuating inactivation as compared to pulsed ( $1 \mathrm{kHz}, 20 / 80 \%$ on/off) stimulation at constant peak power (right). $\mathbf{d}$ For quantification, late measured during pulsed stimulation was normalized to late obtained for the respective continuous-stimulation trials. Each symbol represents a single cell. Data are presented as mean \pm SEM. ${ }^{* *} P<0.01$

GABAergic interneurons $\left(S O M^{\text {IREScre }}:\right.$ eNpHR3.0-EYFP ${ }^{L S L}$ mice) [28]. When continuously stimulated at $594 \mathrm{~nm}$ (5 mW), eNpHR3.0-mediated photo-currents decayed substantially within seconds (Additional file 1: Figure $\mathrm{S} 1 A$ ). In contrast, alternating photo-stimulation with yellow and blue light $(1 \mathrm{kHz}, 50 / 50 \%$ duty cycle, each $5 \mathrm{~mW})$ substantially increased $I_{\text {late }}(t(4)=-3.54, P=$ $0.024)$, while $I_{\text {peak }}$ was moderately reduced $(t(4)=5.94$, $\left.P=4.0 \times 10^{-3}\right)$, resulting in a profound increase of $I_{\text {late }} /$ $I_{\text {peak }}\left(t(4)=-29.0, P=8.4 \times 10^{-6}, n=5\right.$ cells, paired $t$ tests; Additional file 1: Figure S $1 A-C$ ).

In sum, our data demonstrate that blue light attenuates the inactivation of eNpHR3.0-mediated currents during prolonged photo-stimulation at $594 \mathrm{~nm}$ in a mean power-dependent, rather than peak powerdependent, manner. Analogously, $I_{\text {late }}$ is largely determined by the average, rather than the peak, 594-nm light power delivered.
Blue light alone enables efficient and stable long-term photo-stimulation of eNpHR3.0

While the previous experiments provide a strategy to enhance the temporal stability of eNpHR3.0-mediated currents, our initial data employing rescue pulses of blue light (Fig. 1b) already revealed that photo-stimulation at $488 \mathrm{~nm}$ alone is capable of inducing outwards currents in eNpHR3.0-EYFP ${ }^{+}$cells. We therefore set out to systematically investigate the properties of blue-lightevoked photo-stimulation of eNpHR3.0. To this end, cells were photo-stimulated at either $594 \mathrm{~nm}$ or $488 \mathrm{~nm}$ at power levels ranging from 1 to $5 \mathrm{~mW}$ (Fig. 3a). At each power level examined, $I_{\text {peak }}$ values were significantly higher for yellow-light as compared to blue-light stimulation $\left(1 \mathrm{~mW}: t(6)=-6.62, P=5.7 \times 10^{-4} ; 3 \mathrm{~mW}\right.$ : $t(6)=-7.35, P=3.2 \times 10^{-4} ; 5 \mathrm{~mW}: t(6)=-6.57, P=$ $5.9 \times 10^{-4} ; n=7$ cells; paired $t$ tests; Fig. 3a, c). Strikingly, however, current responses evoked by blue-light photo- 

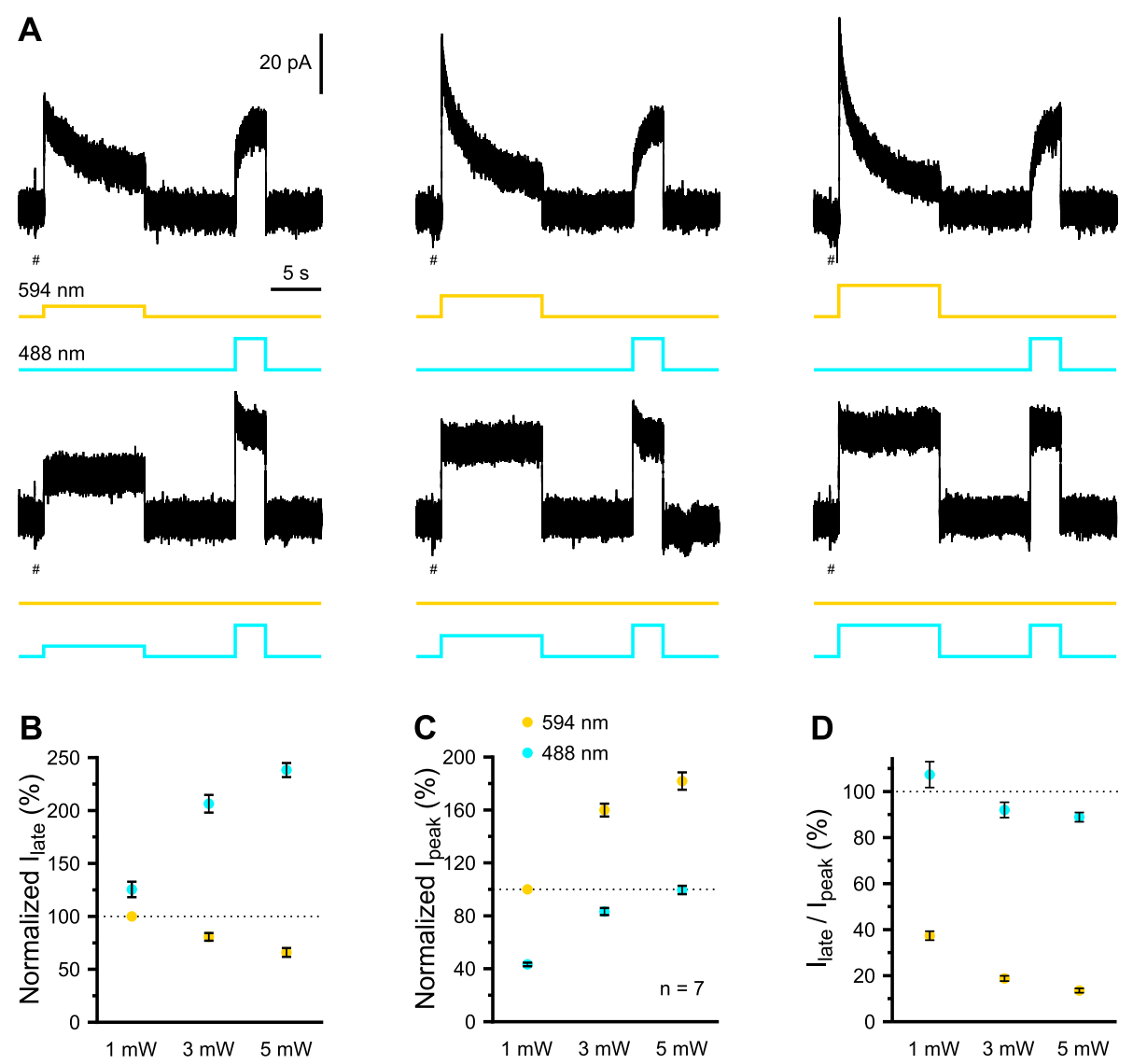

$\mathbf{E}$
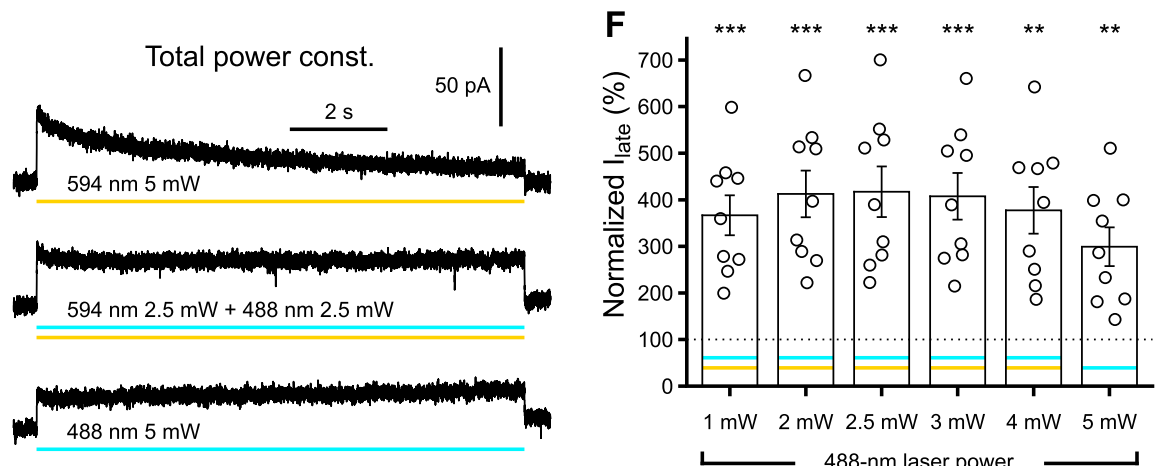

Fig. 3 488-nm light alone enables efficient and stable long-term photo-stimulation of eNpHR3.0. a Sample voltage-clamp recordings from a single cell illustrating the power-dependence of HR-mediated currents evoked by photo-stimulation at $594 \mathrm{~nm}$ (top) or $488 \mathrm{~nm}$ (bottom), delivered at $1 \mathrm{~mW}$ (left), $3 \mathrm{~mW}$ (middle), or $5 \mathrm{~mW}$ (right). Note that photo-currents evoked at $488 \mathrm{~nm}$ display lower peak amplitudes, but high temporal stability across the entire power range examined. At the end of each trial, $488-\mathrm{nm}$ light $(5 \mathrm{~mW})$ was used to accelerate the recovery from inactivation (note the difference in onset kinetics of evoked currents depending on the degree of previous inactivation). Current responses to - 10-mV voltage steps used to monitor access resistance are clipped for clarity (\#). b-d Late (late, $\mathbf{b})$ and peak (I peak, $\mathbf{c}$ ) current amplitudes as

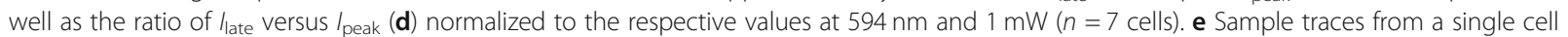
photo-stimulated at $594 \mathrm{~nm}$ and/or $488 \mathrm{~nm}$ and a constant total light power of $5 \mathrm{~mW}$. f Quantification of late measured during the photostimulation regimes indicated normalized to $l_{\text {late }}$ obtained by photo-stimulation at $594 \mathrm{~nm}(5 \mathrm{~mW})$ alone. Note that each combination of $594 \mathrm{~nm}$ plus $488 \mathrm{~nm}$ tested (at constant total power) considerably outperformed photo-stimulation at $594 \mathrm{~nm}$ alone (dotted line). Each symbol represents a single cell. Data are presented as mean \pm SEM. ${ }^{* *} P<0.01,{ }^{* *} P<0.001$

stimulation displayed an extraordinary temporal stability. We quantified this effect by determining $I_{\text {late }} / I_{\text {peak }}$ (Fig. 3d), which we found to be considerably higher for photo-stimulation at $488 \mathrm{~nm}$ as compared to $594 \mathrm{~nm}$ $\left(1 \mathrm{~mW}: t(6)=11.94, P=2.1 \times 10^{-5} ; 3 \mathrm{~mW}: t(6)=19.69\right.$, $P=1.1 \times 10^{-6} ; 5 \mathrm{~mW}: t(6)=30.21, P=8.7 \times 10^{-8} ; n=7$ 
cells, paired $t$ tests; Fig. 3a, d). In addition, whereas the ratio $I_{\text {late }} / I_{\text {peak }}$ strongly declined with increasing power levels for 594-nm light, this dependency was considerably weaker in case of photo-stimulation with blue light (Fig. 3a, d). As a result of this behavior, absolute $I_{\text {late }}$ amplitudes evoked at $594 \mathrm{~nm}$ versus $488 \mathrm{~nm}$ diverged in a power-dependent manner [interaction $(594 / 488 \mathrm{~nm} \times$ power $): F=42.3, \mathrm{df}=1.06, P=4.6 \times$ $10^{-4}$, two-way repeated-measures ANOVA, HuynhFeldt correction; Fig. 3b]. We next sought to determine as to which extent combinations of blue and yellow light, at constant total power $(5 \mathrm{~mW})$, could further increase $I_{\text {late }}$. Strikingly, all tested combinations of 488/ $594 \mathrm{~nm}$ as well as $488 \mathrm{~nm}$ alone clearly outperformed photo-stimulation with pure yellow light as reflected in higher values of $I_{\text {late }}(594 \mathrm{~nm}$ versus all other groups: $P=5.1 \times 10^{-3}$ or lower, post hoc $t$ tests with Bonferroni correction; $F=71.4, \mathrm{df}=1.3, P=2.1 \times 10^{-6}, n=9$ cells, one-way repeated-measures ANOVA, HuynhFeldt correction; Fig. 3e, f). The highest values of $I_{\text {late }}$ were found for combinations with a blue-light fraction of $40-60 \%$, which moderately exceeded $I_{\text {late }}$ values evoked by $488 \mathrm{~nm}$ alone (Fig. 3f).

Collectively, our data unexpectedly reveal that photostimulation at $488 \mathrm{~nm}$ either alone or combined with 594-nm light substantially enhances non-inactivating eNpHR3.0-mediated currents and profoundly improves their temporal stability.

\section{Wavelength dependency of eNpHR3.0-mediated photo- currents measured in $X$. laevis oocytes}

To further quantify the wavelength dependency of eNpHR3.0 and its generalizability to other expression systems, we next performed two-electrode voltageclamp recordings from $X$. laevis oocytes expressing $\mathrm{eN} p \mathrm{HR} 3.0$. We first compared eNpHR3.0 inactivation during long-term $(60 \mathrm{~s})$ illumination at three different wavelengths: $590 \mathrm{~nm}, 532 \mathrm{~nm}$, and $473 \mathrm{~nm}$. We found that 590-nm light could induce the highest initial photo-current amplitudes, but also showed the strongest inactivation (Fig. $4 \mathrm{a}-\mathrm{c}$ ) as compared to $532-\mathrm{nm}$ or 473$\mathrm{nm}$ light of the same intensity $\left(2.6 \mathrm{~mW} / \mathrm{mm}^{2} ; F=345, \mathrm{df}=\right.$ $2, P=6.4 \times 10^{-7}, n=4$ cells, one-way repeated-measures ANOVA, Fig. 4c). We next confirmed that inactivation of eNpHR3.0 is light power-dependent. Photo-current inactivation became more prominent with increasing power at $590 \mathrm{~nm}$ or $532 \mathrm{~nm}(590 \mathrm{~nm}: F=194, \mathrm{df}=2.05, P=1.1 \times$ $10^{-7}, n=5$ cells, one-way repeated-measures ANOVA with Greenhouse-Geisser correction; $532 \mathrm{~nm}: F=21.3$, $\mathrm{df}=1.11, \quad P=0.007, n=5$ cells, one-way repeatedmeasures ANOVA with Greenhouse-Geisser correction; Fig. 4d). In agreement with our results obtained in mice, no obvious inactivation was observed for 473-nm light at powers up to $6.6 \mathrm{~mW} / \mathrm{mm}^{2}(F=3.74, \mathrm{df}=1.92, P=0.074$, $n=5$ cells, one-way repeated-measures ANOVA with Greenhouse-Geisser correction; Fig. 4d).

Following 60-s illumination at $590 \mathrm{~nm}, \mathrm{eNpHR} 3.0$ slowly recovered from inactivation with a weighted time constant of $200 \pm 45 \mathrm{~s}$ in the dark $(F=231, \mathrm{df}=$ $1.29, P=5.3 \times 10^{-8}, n=8$ cells, one-way repeatedmeasures ANOVA, Greenhouse-Geisser correction, Fig. 4e-f). We therefore addressed whether recovery can be accelerated by short-wavelength light. While light pulses $\left(2 \mathrm{~s}, 1 \mathrm{~mW} / \mathrm{mm}^{2}\right)$ at either $473 \mathrm{~nm}$ or 400 $\mathrm{nm}$ accelerated recovery from inactivation, violet light was found to be significantly more effective (control vs. $473 \mathrm{~nm}: P=0.047$; control vs. $400 \mathrm{~nm}: P=1.4 \times$ $10^{-3}$; $473 \mathrm{~nm}$ vs. $400 \mathrm{~nm}: P=0.037$; post hoc $t$ tests with Bonferroni correction; $F=23.6, \mathrm{df}=2, P=1.4 \times$ $10^{-3}, n=3$ cells, one-way ANOVA, Fig. 4g, h).

We next examined if short-wavelength light could alleviate eNpHR3.0 inactivation when co-applied with yellow light. We found that a combination of 590-nm light $\left(2.6 \mathrm{~mW} / \mathrm{mm}^{2}\right)$ with either violet $(400 \mathrm{~nm}, 1 \mathrm{~mW} /$ $\left.\mathrm{mm}^{2}\right)$ or blue $\left(473 \mathrm{~nm}, 1 \mathrm{~mW} / \mathrm{mm}^{2}\right)$ light significantly increased the $I_{\text {late }} / I_{\text {peak }}$ ratio, with violet light being more effective $(590 \mathrm{~nm}$ vs. $590+473 \mathrm{~nm}: P=0.021$; $590 \mathrm{~nm}$ vs. $590+400 \mathrm{~nm}: P=1.1 \times 10^{-3} ; 590+473 \mathrm{~nm}$ vs. $590+400 \mathrm{~nm}: P=0.012$; post hoc $t$ tests with Bonferroni correction; $F=61.3, \mathrm{df}=2, P=9.9 \times 10^{-4}$, oneway repeated-measures ANOVA, Fig. 4i, j). Violet light per se evoked very small, if any, photo-currents $\left(I_{400} /\right.$ $I_{473}=6.5 \pm 1.6 \%, n=4$ cells). Based on the above results, we next explored the possibility to further increase the amplitude of stable photo-currents by examining a combination of green and violet light. Here, the power of $532-\mathrm{nm}$ light was set to $6.6 \mathrm{~mW} /$ $\mathrm{mm}^{2}$, which led to a similar inactivation as compared to $590-\mathrm{nm}$ light at $2.6 \mathrm{~mW} / \mathrm{mm}^{2}$ when applied separately (Fig. 4d). Interestingly, the combination of 1 $\mathrm{mW} / \mathrm{mm}^{2}$ 400-nm light with $6.6-\mathrm{mW} / \mathrm{mm}^{2}$ 532-nm light considerably outperformed the combination with 2.6- $\mathrm{mW} / \mathrm{mm}^{2}$ 590-nm light for its higher photocurrent amplitudes and the eliminated inactivation $\left(I_{\text {late }} / I_{\text {peak }}\right.$ for $590+400 \mathrm{~nm}$ vs. $532+400 \mathrm{~nm}: P=2.3 \times$ $10^{-5}$, post hoc $t$ test with Bonferroni correction; $F=$ $126, \mathrm{df}=2, P=1.2 \times 10^{-5}$, one-way repeated-measures ANOVA; Fig. 4k-m). In addition, whereas $6.6-\mathrm{mW} /$ $\mathrm{mm}^{2}$ 473-nm light alone also induced stable photocurrents with negligible inactivation over $60 \mathrm{~s}$ ( $I_{\text {late }}$ vs. $I_{\text {peak }}: t(3)=2.75, P=0.071, n=4$ cells, paired $t$ test; Fig. 4l), its photo-current amplitude was only about one third of the green-violet combination (Fig. 4k-m).

\section{Inactivation of eNpHR3.0 is pH- and chloride-dependent}

Deprotonation of the Schiff base was suggested to underlie the inactivation of $N p H R[11,22,26]$. We therefore investigated the effect of extracellular $\mathrm{pH}$ 


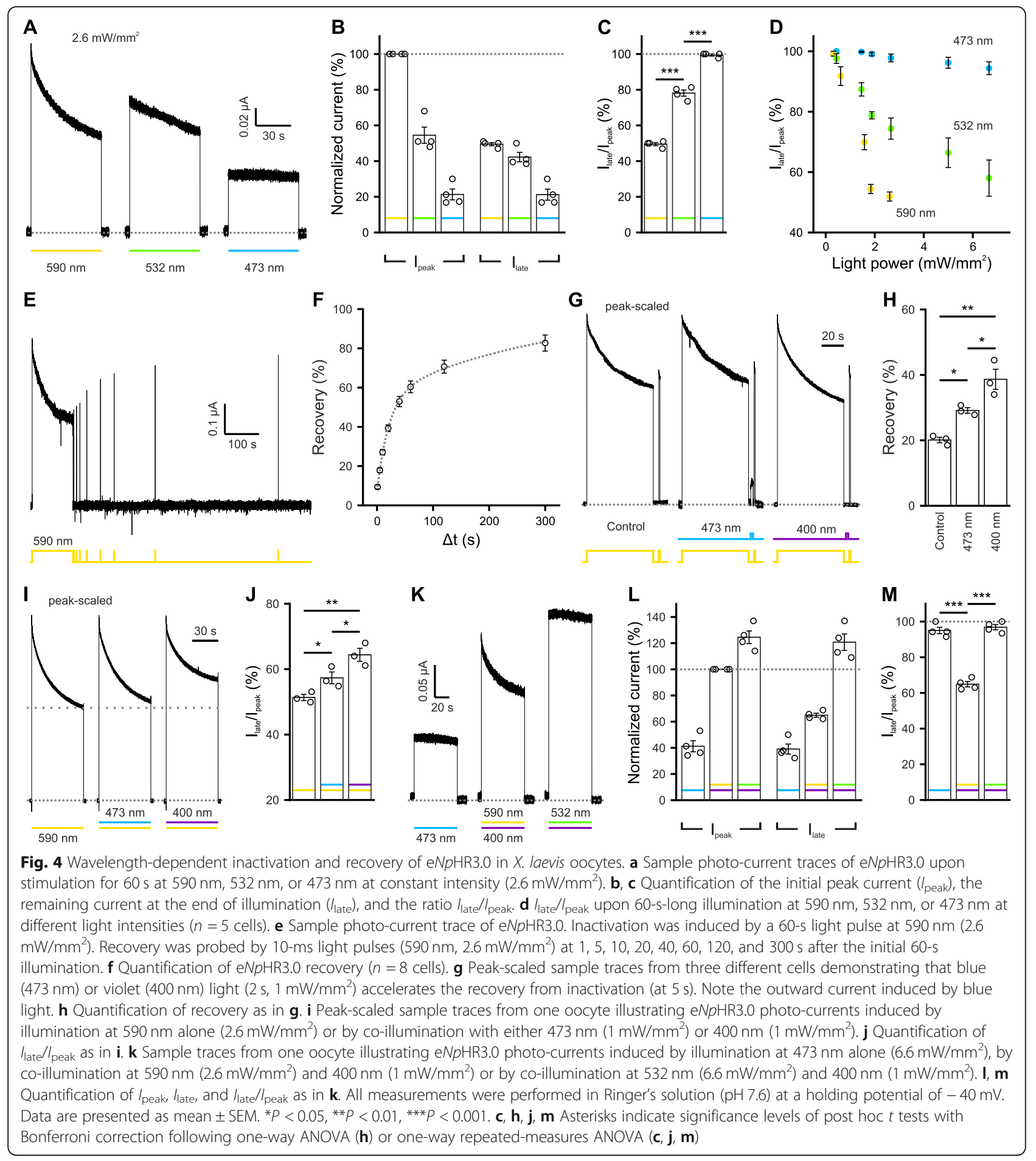

$\left(\mathrm{pH}_{\text {out }}\right)$ on eNpHR3.0 inactivation. At higher $\mathrm{pH}_{\text {out }}$, the Schiff base is expected to lose the proton more easily. Indeed, increased inactivation was observed when $\mathrm{pH}_{\text {out }}$ was increased $\left(F=321, \mathrm{df}=2, P=8.5 \times 10^{-10}\right.$, $n=6$ cells, one-way repeated-measures ANOVA, Fig. 5a). Moreover, as the $\mathrm{pK}_{\mathrm{a}}$ of the Schiff base is strongly dependent on the occupancy of the chloride ion at binding site I of $N p \mathrm{HR}$ [29], chloride binding to $N p \mathrm{HR}$ could stabilize the protonated Schiff base. In agreement with this, lower extracellular chloride concentration $\left(\left[\mathrm{Cl}^{-}\right]_{\text {out }}\right)$ caused stronger inactivation of eNpHR3.0 $\left(F=201, \mathrm{df}=1.4, P=9.7 \times 10^{-7}, n=6\right.$ cells, one-way repeated-measures ANOVA, GreenhouseGeisser correction; Fig. 5b). To gain mechanistic 

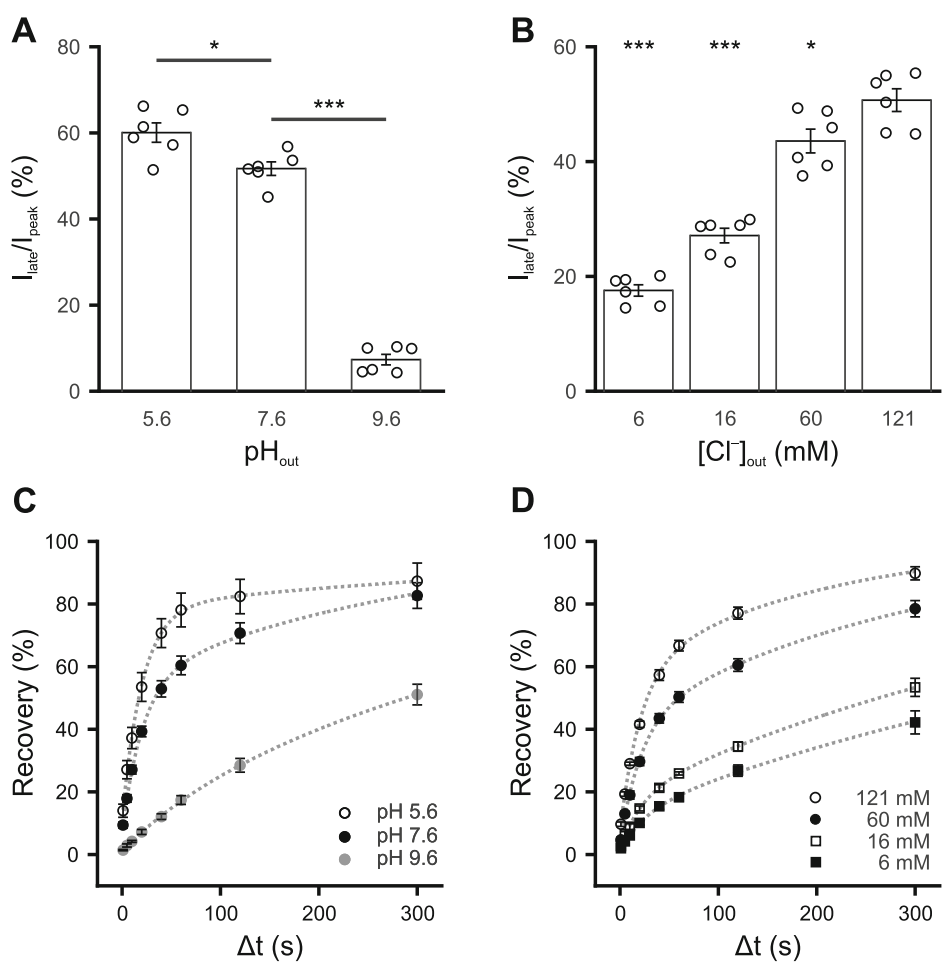

E

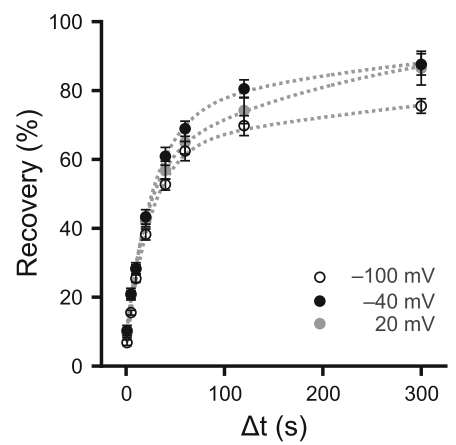

Fig. 5 Mechanistic insight of the inactivation and recovery of eNpHR3.0. a Decreasing extracellular proton concentration enhances inactivation of eNpHR3.0. Currents were measured in the same oocyte in Ringer's solution at pH 5.6, pH 7.6, or pH 9.6. $\mathbf{b}$ Increasing extracellular chloride concentration reduces inactivation of eNpHR3.0. Currents were measured in the same oocyte at different chloride concentrations. Buffers with different chloride concentrations were achieved by mixing Ringer's solution ( $\mathrm{pH}$ 7.6) and NMG-Asp solution (pH 7.6) at different ratio. c Recovery of eNpHR3.0-mediated photo-currents in Ringer's solution at pH $5.6(n=4$ cells), pH $7.6(n=8$ cells), or pH 9.6 ( $n=4$ cells) at a holding potential of $-40 \mathrm{mV}$. $\mathbf{d}$ Recovery of eNpHR3.0-mediated photo-currents at an extracellular chloride concentration of $6 \mathrm{mM}(n=5$ cells), $16 \mathrm{mM}$ ( $n=6$ cells), $60 \mathrm{mM}$ ( $n=6$ cells), or $121 \mathrm{mM}$ ( $n=5$ cells). pH was set to 7.6 and holding potential to $-40 \mathrm{mV}$. Dotted lines in $\mathbf{c}$ and $\mathbf{d}$ represent bi-exponential fits to population data. e Recovery of eNpHR3.0 ( $\mathrm{pH} 7.6)$ at holding potentials of $-100 \mathrm{mV}$ ( $n=7$ cells), $-40 \mathrm{mV}(n=5 \mathrm{cells})$, or $+20 \mathrm{mV}(n=5$ cells). Five hundred ninety-nanometer light at an intensity of $2.6 \mathrm{~mW} / \mathrm{mm}^{2}$ was applied for $60 \mathrm{~s}$ in $\mathbf{a}$ and $\mathbf{b}$, while in $\mathbf{c}-\mathbf{e}$, additional 10-ms $590-\mathrm{nm}$ light pluses at the same intensity were delivered at 1, 5, 10, 20,40,60, 120, and $300 \mathrm{~s}$ after the initial 60-s illumination, as in Fig. 4e. Data are presented as mean \pm SEM. ${ }^{*} P<0.05$, ${ }^{* *} P<0.001$. $\mathbf{a}$, $\mathbf{b}$ Asterisks indicate significance levels of post hoc $t$ tests with Bonferroni correction following one-way repeated-measures ANOVA

insight into the recovery of eNpHR3.0 from inactivation (i.e., reprotonation of the Schiff base), we systematically investigated the effects of $\mathrm{pH}_{\text {out }},\left[\mathrm{Cl}^{-}\right]_{\text {out }}$ as well as membrane potential on the recovery time constant of eNpHR3.0 in the dark. The recovery of eNpHR3.0 from inactivation could be accelerated by either a decrease of $\mathrm{pH}_{\text {out }}$ [tests for $\mathrm{pH}_{\text {out }}$ effects: $F=61$, $\mathrm{df}=2, P=2.9 \times 10^{-6}$; interaction $\left(\mathrm{pH}_{\text {out }} \times \Delta t\right): F=16.9$, $\mathrm{df}=2.66, \quad P=3.3 \times 10^{-5} ; \quad$ mixed-model ANOVA, Greenhouse-Geisser correction; Fig. 5c] or an increase of $\left[\mathrm{Cl}^{-}\right]_{\text {out }}$ [tests for $\left[\mathrm{Cl}^{-}\right]_{\text {out }}$ effects: $F=176, \mathrm{df}=3, P=9.9 \times$ $10^{-11}$; interaction $\left(\left[\mathrm{Cl}^{-}\right]_{\text {out }} \times \Delta t\right): F=49.6, \mathrm{df}=4.97, P=$ 
$1.5 \times 10^{-13}$; mixed-model ANOVA, Greenhouse-Geisser correction; Fig. 5d]. This indicates that the proton for reprotonation of the Schiff base comes from the extracellular space. Interestingly, no significant difference of the recovery time of eNpHR3.0 at different membrane potentials was observed when $\left[\mathrm{Cl}^{-}\right]_{\text {out }}$ was $121 \mathrm{mM}$ at $\mathrm{pH} 7.6$ [tests for membrane potential effects: $F=3.63, \mathrm{df}=2, P=$ 0.077 ; interaction (membrane potential $\times \Delta t$ ),$F=2.14$, $\mathrm{df}=2.85, P=0.13$; mixed-model ANOVA, GreenhouseGeisser correction; Fig. 5e)]. Taken together, the data suggest that the proton for the reprotonation of the Schiff base originates from the extracellular side, and its uptake is always facilitated by the binding of chloride, and vice versa.

\section{Blue-light-induced photo-stimulation of eNpHR3.0 enables efficient long-term hyperpolarization and inhibition}

We next investigated whether the superior properties of photo-stimulation using short-wavelength light found in voltage-clamp experiments translate into a higher efficiency of long-term neuronal inhibition. We focused on blue light as the use of multiple wavelengths might potentially represent a complicating factor in in vivo applications (see the "Discussion" section)-in spite of lower photo-current amplitudes as compared to the green-violet combination (Fig. 4). Using current-clamp measurements from CA1 pyramidal cells in acute brain slices of mice, repetitive 1-s current injections via the patch pipette were used to evoke action potential firing in the presence of ionotropic glutamate and GABA receptor antagonists (Fig. 6a). Photo-stimulation of eNpHR3.0 at $594 \mathrm{~nm}(5$ $\mathrm{mW}$ ) for $1 \mathrm{~min}$ suppressed action potential discharge in a highly time-dependent manner: whereas firing in response to the first test pulse $(500 \mathrm{~ms}$ after the onset of light stimulation) was virtually abolished, the inhibitory effect almost disappeared for the second as well as all subsequent test pulses (Fig. 6a, b). In contrast, photostimulation at $488 \mathrm{~nm}(5 \mathrm{~mW})$ reliably inhibited action potential discharge during the entire 1-min illumination period [interaction (control $/ 488 \mathrm{~nm} / 594 \mathrm{~nm} \times$ test pulse number): $F=13.2, \mathrm{df}=4.6, P=1.7 \times 10^{-7}, n=10$ cells, two-way repeated-measures ANOVA, Huynh-Feldt

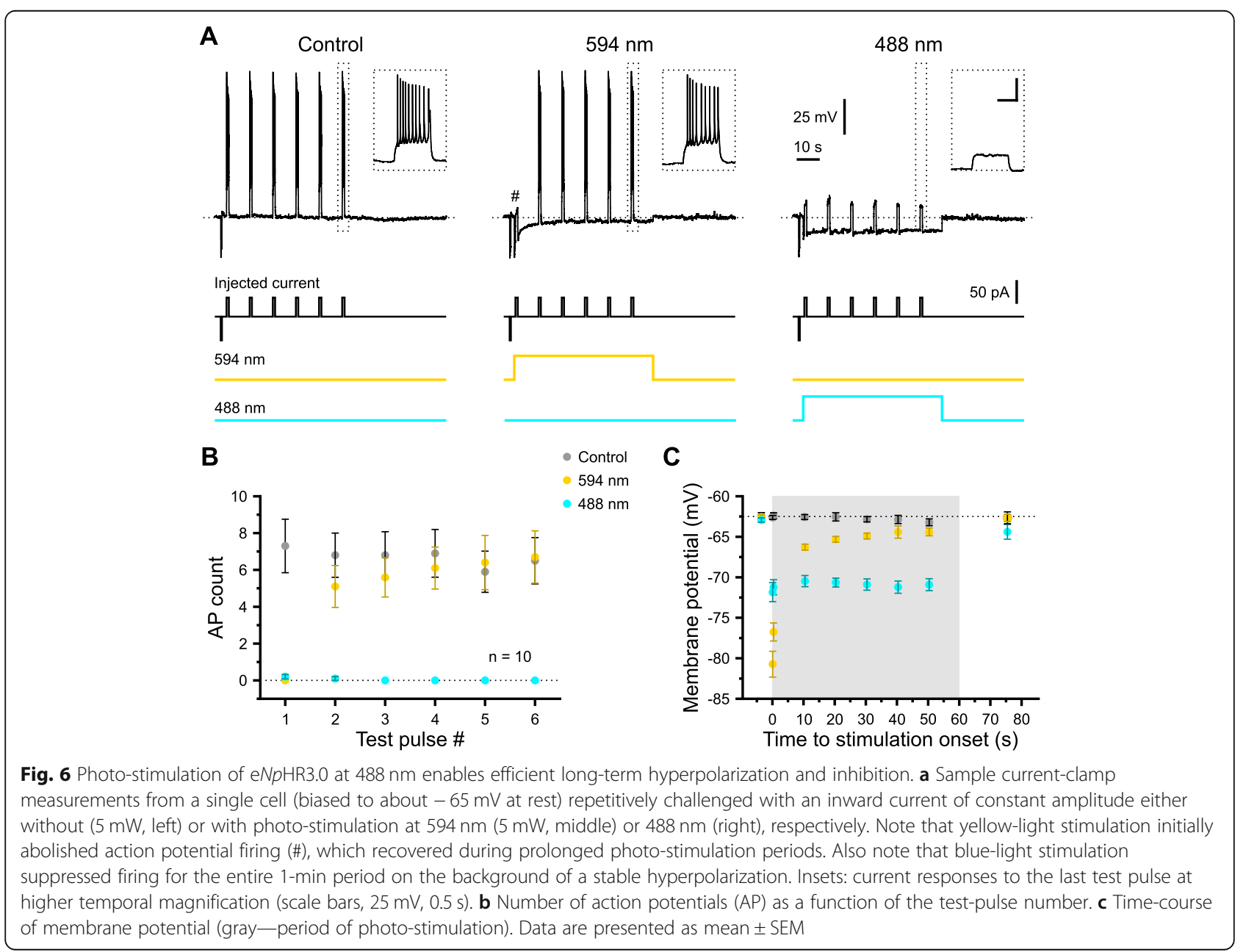


correction; Fig. 6a, b]. Furthermore, photo-stimulation with yellow light resulted in a pronounced, but transient hyperpolarization, whereas photo-stimulation at $488 \mathrm{~nm}$ induced a highly stable hyperpolarizing response in all cells analyzed. Accordingly, a two-way repeated-measures ANOVA yielded a highly significant interaction between the independent variables $(F=71.2, \mathrm{df}=5.0, P=3.1 \times$ $10^{-20}, n=10$ cells, Huynh-Feldt correction; Fig. 6a, c).

\section{Wavelength and duration dependence of chloride loading} during photo-stimulation of eNpHR3.0

As eNpHR3.0 mediates chloride uptake, prolonged activation of eNpHR3.0 may affect $\left[\mathrm{Cl}^{-}\right]_{\text {in }}$ and, hence, shift the reversal potential of $\mathrm{GABA}_{\mathrm{A}}$ receptordependent currents $\left(E_{\mathrm{GABA}}\right)$ into the positive direction [30]. We therefore quantified the wavelength and duration dependence of photo-stimulation-induced changes in $E_{\mathrm{GABA}}$ using gramicidin perforated-patch current-clamp recordings from CA1 pyramidal cells. In the presence of antagonists of ionotropic glutamate receptors $\left(10 \mu \mathrm{M}\right.$ DNQX, $50 \mu \mathrm{M}$ APV) and voltage-gated $\mathrm{Na}^{+}$ $\left(0.5 \mu \mathrm{M}\right.$ TTX) and $\mathrm{Ca}^{2+}(100 \mu \mathrm{M} \mathrm{CdCl})$ channels, cells were challenged with a saturating puff of the $\mathrm{GABA}_{\mathrm{A}}$ receptor agonist isoguvacine $(100 \mu \mathrm{M}, 2 \mathrm{~s})$. As demonstrated before, the peak membrane potential $\left(V_{\text {peak }}\right)$ approximates $E_{\mathrm{GABA}}$ under these conditions [31]. We found that a 30-slong photo-stimulation at $488 \mathrm{~nm}(5 \mathrm{~mW})$ slightly, but significantly, shifted $V_{\text {peak }}$ by $+1.9 \pm 0.6 \mathrm{mV}(t(6)=-3.15$, $P=0.020, n=7$ cells, paired $t$ test; Fig. 7a, b). This effect was dose-dependent, since a more pronounced shift in $V_{\text {peak }}$ by $+7.2 \pm 0.7 \mathrm{mV}\left(t(12)=-9.77, P=4.6 \times 10^{-7}, n=\right.$ 13 cells, paired $t$ test; Fig. 7c, d) was observed for a photostimulation period of $120 \mathrm{~s}(488 \mathrm{~nm}, 5 \mathrm{~mW})$. In contrast, yellow-light photo-stimulation for $120 \mathrm{~s}(594 \mathrm{~nm}, 5 \mathrm{~mW})$ did not significantly affect $V_{\text {peak }}(+0.0 \pm 0.7 \mathrm{mV}(t(9)=$ 0.027, $P=0.98, n=10$ cells, paired $t$ test; Fig. 7e, f)). Importantly, resting membrane potential $\left(V_{\text {rest }}\right)$ was unaffected by either photo-stimulation paradigm $(P>0.1$, paired $t$ tests; Fig. 7a-f), arguing against a major phototoxic effect. In summary, our data demonstrate that photo-stimulation of eNpHR3.0 with blue light not only increases steady-state currents (Fig. 3) and membrane potential changes (Fig. 6), but also enhances the eNpHR3.0mediated increase in $\left[\mathrm{Cl}^{-}\right]_{\text {in }}$.

Consequently, alterations in network dynamics resulting from $E_{\mathrm{GABA}}$ changes represent a potential experimental constraint related to the use of eNpHR3.0. We examined this possibility in hippocampal slices obtained from neonatal mice (P3-6), i.e., at a developmental stage when depolarizing GABAergic transmission drives synchronized network activity $[28,32]$. In agreement with published data [33], pharmacological inhibition of the chloride cotransporter NKCC1 using bumetanide $(10 \mu \mathrm{M})$ largely abolished bursts of spontaneous postsynaptic currents
(PSCs), confirming that synchronized network activity is strongly $\left[\mathrm{Cl}^{-}\right]_{\text {in }}$-dependent at this age (Additional file 2: Figure $\mathrm{S} 2 A, B$ ). We predicted that, in the continuous presence of bumetanide, photo-stimulation of Emx1+ CA1 pyramidal cells would rescue PSC bursts by elevating $\left[\mathrm{Cl}^{-}\right]_{\text {in }}$. Indeed, following the offset of blue-light illumination $(60 \mathrm{~s}, 5 \mathrm{~mW})$, PSC bursts transiently reappeared (PSC burst count per 20-s bin: before stim $0.35 \pm 0.19$, after stim $4.25 \pm 0.66, t(3)=-6.57, n=4$ cells, $P=7.2 \times$ $10^{-3}$, paired $t$ test; Additional file 2: Figure $\mathrm{S} 2 A-C$ ). Thus, these data provide proof-of-principle evidence that activation of eNpHR3.0 may alter neuronal population dynamics due to a shift in $E_{\mathrm{GABA}}$. We further reasoned that such effects may be less pronounced in slices obtained at a later developmental stage (P11-12), when KCC2-dependent chloride extrusion is more effective [34], synchronized network events are virtually absent and spontaneous excitatory PSCs (EPSCs) mainly reflect miniature release. In line with this prediction, long-lasting $(5 \mathrm{~min})$ photostimulation at $488 \mathrm{~nm}(5 \mathrm{~mW})$ failed to alter EPSC frequency after stimulation offset, and EPSC frequency was stable for the following $10 \mathrm{~min}(F=0.99, \mathrm{df}=2$, $P=0.41, n=6$ cells, one-way repeated-measures ANOVA; Additional file 2: Figure S2D-F). The latter observation also argues against a major photo-toxic effect on synaptic release due to extended photostimulation with blue light.

\section{Discussion}

Up to now, the chloride pump eNpHR3.0 is one of the most popular optogenetic tools for hyperpolarization of excitable cells. Like many other rhodopsin-based optogenetics tools, inactivation upon light illumination is a main obstacle hindering the application of eNpHR3.0 [24]. Here, we systematically studied the inactivation of $\mathrm{eNpHR} 3.0$ caused by long-term illumination in both murine hippocampal neurons and $X$. laevis oocytes. We expect that congruent findings made in these two different expression systems reflect the property of the protein itself, largely eliminating the influence of possible protein-protein interactions in the host system. Inactivation upon long-term illumination, slow recovery by thermal decay in the dark, and the accelerated recovery by blue-light illumination of eNpHR3.0 were similarly observed in both host cells. In addition, in both systems, the temporal stability of eNpHR3.0 is improved under optimized photo-stimulation conditions, such as co-application of yellow and blue light, green and violet light, or blue light alone.

\section{Biophysical mechanism of eNpHR3.0 inactivation and recovery}

Inactivation of the homologue protein $\mathrm{HsHR}$ from Halobacterium salinarum was proven to be the consequence 

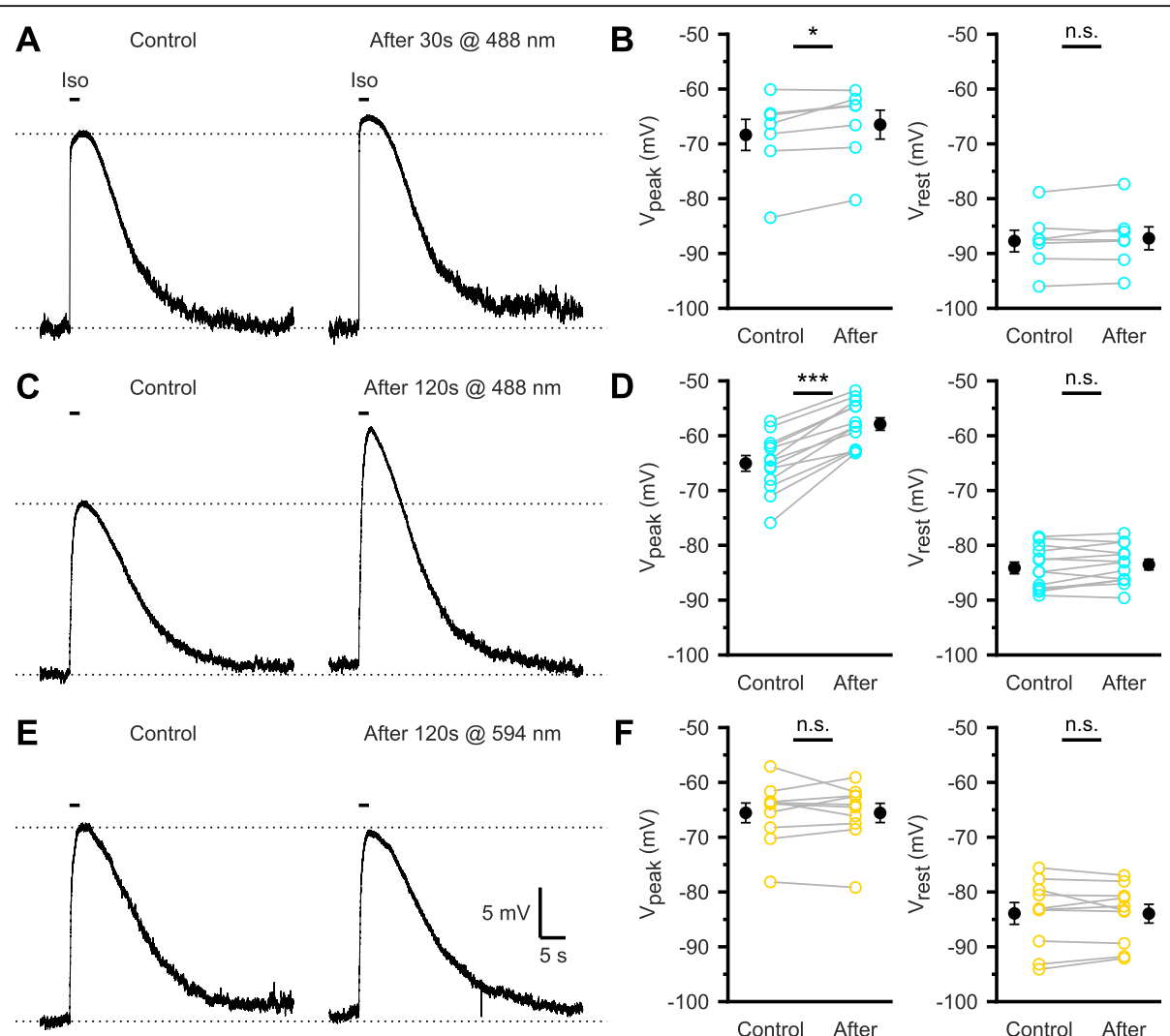

Fig. 7 Wavelength and duration dependence of chloride loading due to photo-stimulation of eNpHR3.0. a Sample gramicidin perforated-patch recording of membrane potential in response to puff application of isoguvacine (Iso, $100 \mu \mathrm{M}, 2 \mathrm{~s}$ ) before (Control) and after photo-stimulation at $488 \mathrm{~nm}$ for $30 \mathrm{~s}(5 \mathrm{~mW})$. Dotted lines indicate resting $\left(V_{\text {rest }}\right)$ and peak $\left(V_{\text {peak }}\right)$ membrane potential measured before photo-stimulation. Note that $V_{\text {peak }}$ approximates $E_{\text {GABA }}$ under our recording conditions. $\mathbf{b}$ Quantification of $V_{\text {rest }}$ and $V_{\text {peak }}$ before and after photo-stimulation. $\mathbf{c}$, $\mathbf{d}$ As in $\mathbf{a}$ and b, but photo-stimulation was performed for $120 \mathrm{~s}$ at $488 \mathrm{~nm}(5 \mathrm{~mW}$ ). e, f As in $\mathbf{a}$ and $\mathbf{b}$, but photo-stimulation was performed for $120 \mathrm{~s}$ at $594 \mathrm{~nm}$ $(5 \mathrm{~mW})$. Experiments were performed at P4-10. Data are presented as mean \pm SEM. n.s. not significant, ${ }^{* *} P<0.01,{ }^{* *} P<0.001$

of accumulation of an M-like intermediate from a branched photo-cycle with a deprotonated Schiff base [26, 35-37]. Therefore, inactivation of $N p H R$ was naturally attributed to a similar mechanism, but not further investigated [11,22]. To gain additional insights into the mechanism of inactivation of eNpHR3.0, we characterized the effects of different illumination and extracellular ionic conditions. Light power and wavelength dependences of inactivation may result from different photochemical processes underlying different light stimuli. The proton and chloride dependences of inactivation strongly support the Schiff base deprotonation hypothesis. Unlike bacteriorhodopsin (BR), where the positive charge of the protonated Schiff base is counterbalanced by its aspartate $\mathrm{D} 85$, in $N p \mathrm{HR}$, this negative charge is provided by the binding of a chloride ion [38]. Accordingly, a decrease of either extracellular proton or chloride concentration will increase the chance of deprotonation of the Schiff base, although the Schiff base of $N p \mathrm{HR}$ was suggested to be never deprotonated during the chloride pumping cycle [39-41]. To effectively transport chloride, the Schiff base also needs to be protonated to facilitate chloride binding. Therefore, $N p \mathrm{HR}$ intermediates with deprotonated Schiff base are stable and nonpumping. Indeed, the slow kinetics of recovery from inactivation of eNpHR3.0 is also consistent with the stable and non-pumping feature of this M-like intermediate. Collectively, our data indicate that eNpHR3.0 inactivation following long-term illumination is due to formation of an M-like intermediate with a deprotonated Schiff base (Fig. 8).

We observed that the recovery time of eNpHR3.0 strongly depends on $\mathrm{pH}_{\text {out }}$, indicating that the proton for reprotonation of the deprotonatated Schiff base comes from the extracellular side. In addition, extracellular chloride could also affect the reprotonation of the Schiff base by regulating the $\mathrm{pKa}$ through binding to the binding site I [29]. In keeping with this, we found that lowering $\left[\mathrm{Cl}^{-}\right]_{\text {out }}$ slowed down the recovery of eNpHR3.0. Changes of membrane potential will always cause opposite effects 
on proton or chloride binding to the Schiff base. Accordingly, no difference in recovery time was observed at different membrane potentials. It is intriguing to ask what the proton source is under the blue-light-induced recovery scenario. We argue that the proton is also from the extracellular side: First, in the structurally related $H s \mathrm{HR}$, proton uptake has been experimentally proven to occur from the extracellular channel upon restoration of $\mathrm{H}_{410}$ to the initial state by blue-light absorption [26]. Second, in BR, pump activity can be inhibited by additional blue light, in which blue-light absorption decays the $\mathrm{M}_{412}$ intermediate to the initial $\mathrm{BR}_{568}$ state by reprotonation of the Schiff base from the extracellular side [42-44] (Fig. 8). Third, a crystallography study proposed that the reprotonation of the Schiff base occurs after retinal isomerization when the cytosolic interhelical space is already closed, suggesting that the proton is from the extracellular side [45]. Beyond that, our findings may have broader utility via their application to training statistical models for the computational design of optimized $\mathrm{NpHR}$ variants [46].

\section{Short-wavelength light enables optimized spatiotemporal control of eNpHR3.0}

The inactivation of $\mathrm{NpHR} 3.0$ during continuous illumination $[11,22]$ limits its utility for long-lasting $(>10 \mathrm{~s})$ neuronal inhibition (see also [15]). However, prolonged silencing of neuronal populations is typically a critical requirement for analyzing their involvement in network oscillations and behaviors. We here confirm that inactivation increases with increasing green or yellow light power (Fig. 3), which could be particularly problematic if expression levels are low, as is the case in many transgenic models. Importantly, the present study reveals that, independent of expression system, inactivation is highly wavelength-dependent, being profoundly reduced for blue as compared to green or yellow light (Figs. 3 and 4). This may be of great practical importance as, within the tissue, light power declines with increasing distance from the fiber tip [15]. Consequently, when using yellow light, cells that lie close to the light source (i.e., that are exposed to a comparatively high light power) will not only exhibit higher peak photo-current amplitudes, but also a more pronounced to inactivation than those at larger distances. In other words, in addition to increasing the temporal stability of eNpHR3.0-mediated currents within individual cells, blue light is expected to minimize differences in inactivation between spatially distributed cells.

Comparing continuous with high-frequency photostimulation regimes revealed that blue light attenuates the yellow-light-induced eNpHR3.0 inactivation in a mean power-dependent manner (Fig. 2). This finding justifies the use of continuous blue-light illumination, which can be delivered using simpler hardware solutions. As compared to photo-stimulation with blue light alone, co-

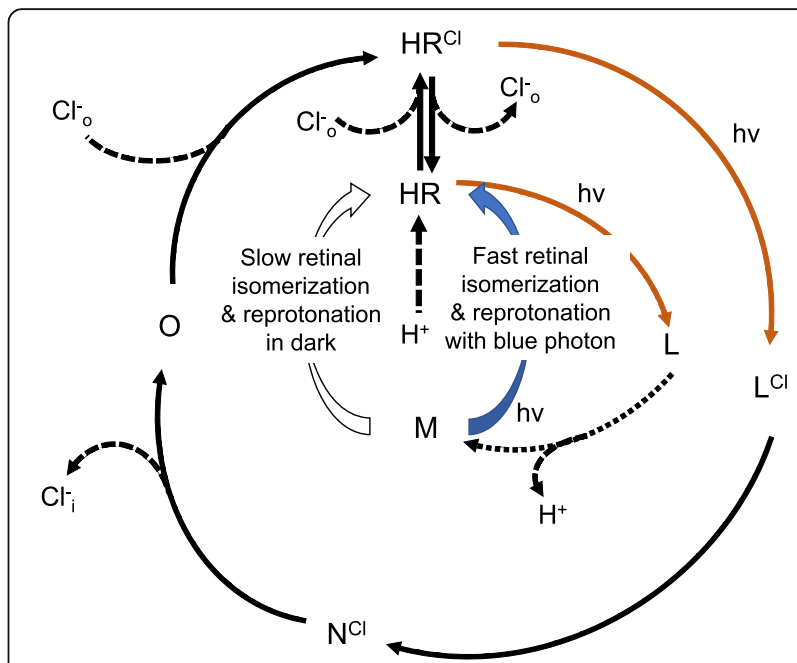

Fig. 8 Proposed photo-cycle of NpHR. An extracellular chloride ion is bound to the Schiff base lysine of $\mathrm{NpHR}$ at resting state, with $K_{\mathrm{m}}=16 \mathrm{mM}$ [11]. Photon absorption (with maximum at $580 \mathrm{~nm}$ ) triggers the isomerization of retinal and starts the photo-cycle, containing intermediates $\mathrm{K}$ (omitted here), $\mathrm{L}, \mathrm{N}$, and $\mathrm{O}$. The chloride ion is released into the cytosol during the transition from $\mathrm{N}$ to $\mathrm{O}$, and uptake of a chloride ion from the extracellular side takes place in the recovery from $\mathrm{O}$ to the initial state. $\mathrm{HR}$ without a bound chloride ion is prone to deprotonation of the Schiff base in the $L$ state (indicated by dashed line), leading to formation of $\mathrm{M}$. This intermediate is long-lived and absorbs similarly as $\mathrm{HR}_{410}$ (or $\mathrm{M}_{412}$ in BR) from Halobacterium salinarum. The uptake of the proton for reprotonation of the $\mathrm{M}$ intermediate is very slow in dark (open arrow) but fast after absorption of a blue photon (blue arrow). Our data support deprotonation of the chloride-free $L$ state (indicated by broken line)

illumination with yellow light produced non-inactivating currents of even higher amplitude. Largest photo-currents were found for combinations with a blue-light fraction of $40-60 \%$ (Fig. 3). The temporal stability of eNpHR3.0-mediated currents, however, was maximal for pure 488-nm illumination and not further enhanced by co-illumination with yellow light (Fig. 3). In oocytes, similarly stable eNpHR3.0-mediated photo-currents were obtained by combining green with violet light, while violet light per se evoked negligible photo-currents when applied in isolation (Fig. 4). In addition, the corresponding steady-state amplitudes exceeded those evoked by photo-stimulation with pure blue light (Fig. 4). This may render the combination of green and violet light the preferred photo-stimulation regime, if high-amplitude photo-currents are required. However, it should be considered that violet and green light exhibit a differential distance-dependent power attenuation in brain tissue, which may result in larger spatial inhomogeneities as outlined above.

In sum, in combination with the fast intrinsic on-/offkinetics of eNpHR3.0 in the millisecond range, the protocols described here provide for an optimized 
spatiotemporal control of eNpHR3.0 photo-activation for flexible neuronal inhibition.

\section{Practical considerations}

Light-driven chloride pumps use subtractive inhibition (i.e., hyperpolarization) and, consequently, operate independently of the electrochemical chloride gradient [21]. This is a potential advantage over chloride-conducting channelrhodopsins (e.g., GtACR1), which act in a $\left[\mathrm{Cl}^{-}\right]_{\mathrm{in}^{-}}$ dependent manner and, for instance, can depolarize presynaptic terminals and evoke neurotransmitter release [18]. However, a general constraint of using ion pumps for neuronal silencing results from changes in reversal potential of the ionic species transported. For example, the proton pump archaerhodopsin (eArch3.0) was shown to induce a $\mathrm{pH}$-dependent $\mathrm{Ca}^{2+}$ influx that enhanced spontaneous vesicular release [18]. Analogously, the chloride pump eNpHR3.0 can increase $\left[\mathrm{Cl}^{-}\right]_{\text {in, }}$ which shifts $E_{\mathrm{GABA}}$ and may facilitate depolarizing GABAergic/glycinergic signaling that could counteract the eNpHR3.0-mediated hyperpolarization $[25,30]$. We here show that $E_{\mathrm{GABA}}$ shifts are larger for photo-stimulation with blue as compared to yellow light (Fig. 7), in agreement with the increase in charge transfer for prolonged stimulation periods (Fig. 3). While manipulations of $E_{\mathrm{GABA}}$ may be useful, e.g., for dissecting the contribution of GABAergic signaling to network dynamics under physiological or pathophysiological conditions [25], they also impose an experimental constraint to the use of eNpHR3.0 for neuronal silencing. We provide plausibility evidence that $E_{\mathrm{GABA}}$ shifts may transiently induce aberrant network activity in the post-stimulation period at P3-6 (Additional file 2: Figure $\mathrm{S} 2 A-C$ ), whereas such effects were not observed at a later developmental stage (Additional file 2: Figure $\mathrm{S} 2 D-F$ ), when chloride extrusion has been shown to be more efficient [34]. In the general case, the magnitude of $E_{\mathrm{GABA}}$ shifts can hardly be predicted, as it depends on several parameters (chloride extrusion capacity, resting chloride conductance, etc.), and should be examined for a given experimental setting. Additionally, due to the fast deactivation kinetics of eNpHR3.0, abrupt termination of photostimulation can lead to rebound depolarization and action potential firing [30, 47]. This effect is due to network-based mechanisms [28], chloride loading, and/or activation of voltage-gated conductances (e.g., $\mathrm{H}$-current, T-type $\mathrm{Ca}^{2+}$ current) and can be readily attenuated by replacing a steplike termination of photo-stimulation with a more gradual decrease in light power [18]. Finally, while our data do not provide direct evidence for photo-toxicity induced by prolonged illumination with blue light (Fig. 7 and Additional file 2: Figure S2), photo-stimulation invariably heats tissue and could thus affect a number of temperature-dependent physiological processes. Indeed, thermal constraints of optogenetics are well documented
[48], further underlying the need for well-designed control experiments.

\section{Conclusions}

Taken together, our study provides a novel approach for long-term optogenetic silencing that is based on an optimization of photo-stimulation, rather than protein engineering. For short-term optogenetic inhibition, yellow light remains the preferred choice for its capability to induce large photo-currents and its favorable tissue penetration properties. However, when prolonged inhibition is required, photo-stimulation with blue light (either alone or in combination with yellow light) is advantageous due to its superior temporal stability. Besides, our study also provides alternative photo-simulation schemes for longterm inhibition, as we observed in oocytes that a greenviolet combination outperformed blue light in terms of photo-current amplitudes without any obvious inactivation. In sum, our study provides easy-to-implement photo-stimulation approaches for the light-driven chloride pump eNpHR3.0 that are associated with an extraordinary temporal stability of pump currents and thus render eNpHR3.0 suitable for long-term neuronal inhibition.

\section{Methods}

\section{Ethics statement}

All experimental procedures were carried out with approval from the local government and complied with European Union norms (Directive 2010/63/EU).

\section{Animals}

Experiments were performed on acute brain slices prepared from mice of both sexes at postnatal day (P) 4-13. Pyramidal cell-specific expression of an eNpHR3.0-EYFP fusion protein was achieved by crossing homozygous female Emx $1^{\text {IREScre }}$ mice (The Jackson Laboratory, stock no. 005628) [49] to homozygous male mice of the Ai39 cre-reporting strain (The Jackson Laboratory, stock no. 014539) [50]. For experiments on SOM interneurons, homozygous SOM ${ }^{\text {IRESCre }}$ mice (The Jackson Laboratory, stock no. 013044) [51] were crossed to homozygous Ai39 mice. Animals were housed in standard cages with 12-h light/12-h dark cycles.

\section{Preparation of brain slices}

Animals were decapitated under deep isoflurane anesthesia. The brain was removed quickly and transferred into ice-cold saline containing (in $\mathrm{mM}$ ) 125 $\mathrm{NaCl}, 4 \mathrm{KCl}, 10$ glucose, $1.25 \mathrm{NaH}_{2} \mathrm{PO}_{4}, 25 \mathrm{NaHCO}_{3}$, $0.5 \mathrm{CaCl}_{2}$, and $2.5 \mathrm{MgCl}_{2}$, bubbled with $5 \% \mathrm{CO}_{2} / 95 \%$ $\mathrm{O}_{2}(\mathrm{pH}, 7.4)$. Horizontal brain slices containing the hippocampus $(350 \mu \mathrm{m})$ were cut on a vibratome and stored for at least $1 \mathrm{~h}$ before their use at room temperature in artificial cerebrospinal fluid (ACSF) 
containing (in $\mathrm{mM}$ ) $125 \mathrm{NaCl}, 4 \mathrm{KCl}, 10$ glucose, 1.25 $\mathrm{NaH}_{2} \mathrm{PO}_{4}, 25 \mathrm{NaHCO}_{3}, 2 \mathrm{CaCl}_{2}$, and $1 \mathrm{MgCl}_{2}$, bubbled with $5 \% \mathrm{CO}_{2} / 95 \% \mathrm{O}_{2}(\mathrm{pH}, 7.4)$. For recordings, slices were placed into a submerged-type recording chamber on the microscope stage (Nikon Eclipse FN1, Nikon Instruments Inc.) equipped with near-infrared differential interference contrast optics (ACSF flow rate $\sim 3 \mathrm{ml}$ $\left.\min ^{-1}\right)$. Experiments were performed at near physiological temperature $\left(32-34{ }^{\circ} \mathrm{C}\right)$.

\section{Electrophysiology in brain slices}

Electrophysiological signals were acquired using a Multiclamp 700B amplifier, a 16-bit AD/DA board (Digidata $1550 \mathrm{~A}$ ) and the software pClamp 10 (Molecular Devices). Signals were low-pass filtered at $3 \mathrm{kHz}$ and sampled at $10 \mathrm{kHz}$. For patch-clamp recordings of photocurrents from CA1 pyramidal cells, glass pipettes (4-7 $\mathrm{M} \Omega$ ) were filled with the following solution (in $\mathrm{mM}$ ): 40 $\mathrm{KCl}, 100 \mathrm{~K}^{+}$-gluconate, $1 \mathrm{CaCl}_{2}, 11$ EGTA, 10 HEPES, 2 $\mathrm{Mg}^{2+}$-ATP, and $0.3 \mathrm{Na}^{+}$-GTP (pH adjusted to 7.25 with $\mathrm{KOH})$. Whole-cell voltage-clamp recordings were performed at a holding potential of $-70 \mathrm{mV}$. In whole-cell current-clamp measurements, the resting membrane potential was manually biased to about $-65 \mathrm{mV}$ via current injection. Voltages were not corrected for liquid junction potential (LJP). Except for experiments illustrated in Fig. $1 \mathrm{a}-\mathrm{d}$, a blue-light pulse $(488 \mathrm{~nm}, 3 \mathrm{~s}, 5 \mathrm{~mW})$ was routinely applied at the end of each stimulation trial to accelerate the recovery of eNpHR3.0-mediated currents from inactivation (for an example, see Fig. 3a). The recovery from inactivation of eNpHR3.0-mediated currents (Fig. 1c) was fitted, separately for each cell, by a monoexponential function of the following form:

$$
\text { recovery }=a \times e^{\frac{-\Delta t}{\tau}}+c
$$

where $\Delta t$ is the latency of the test pulse onset. The offset $c$ was constrained to $100 \%$.

Due to a high intercellular variability of input resistances, the amplitude of injected currents used to evoke action potential firing in current-clamp experiments (see Fig. 4) was separately set for each cell and kept constant throughout the recording. Using a series of repetitive current injections ( $1 \mathrm{~s}, 5-\mathrm{pA}$ increments), the amplitude was determined from the largest current step that failed to induce action potentials under brief $(2 \mathrm{~s}, 5 \mathrm{~mW})$ photo-stimulation at $488 \mathrm{~nm}$.

For gramicidin perforated-patch current-clamp recordings from CA1 pyramidal cells, glass pipettes were filled with the following solution (in $\mathrm{mM}$ ): $140 \mathrm{~K}^{+}$-gluconate, $1 \mathrm{CaCl}_{2}, 11$ EGTA, $1 \mathrm{MgCl}_{2}$, and 10 HEPES ( $\mathrm{pH}$ adjusted to 7.3 with $\mathrm{KOH}$ ), additionally supplemented with $50 \mu \mathrm{g} / \mathrm{ml}$ gramicidin. Here, measured voltages were offline-corrected for LJP $(16.5 \mathrm{mV})$. Recordings were performed at zero current.

Whole-cell voltage-clamp recordings of spontaneous PSCs were performed at a holding potential of -70 $\mathrm{mV}$ without correction for LJP. At P3-6, glass pipettes were filled with (in $\mathrm{mM}$ ) $40 \mathrm{KCl}, 100 \mathrm{~K}^{+}$-gluconate, 1 $\mathrm{CaCl}_{2}, 11$ EGTA, 10 HEPES, $2 \mathrm{Mg}^{2+}$-ATP, and 0.3 $\mathrm{Na}^{+}$-GTP (pH adjusted to 7.25 with $\mathrm{KOH}$ ). Bursts of spontaneous PSCs were visually detected using the following criteria: (I) duration $>400 \mathrm{~ms}$ and (II) amplitude $>200 \mathrm{pA}$. For measurement of EPSCs at P11-12, glass pipettes were filled with (in $\mathrm{mM}$ ) $8 \mathrm{KCl}, 140 \mathrm{~K}^{+}$gluconate, $1 \mathrm{CaCl}_{2}, 11 \mathrm{EGTA}, 10 \mathrm{HEPES}, 2 \mathrm{Mg}^{2+}$-ATP, and $0.3 \mathrm{Na}^{+}$-GTP (pH adjusted to 7.25 with $\mathrm{KOH}$ ). EPSCs were detected using a template-matching algorithm implemented in pClamp 10.

\section{Molecular biology and genetics}

eNpHR3.0 DNA was cloned into oocyte expression vectors, based on the plasmid pGEMHE 22, a derivative of pGEM3z (Promega). NheI-linearized plasmid DNA was used for the in vitro generation of cRNA with the AmpliCap-MaxT7 High Yield Message Maker Kit (Epicentre Biotechnologies).

\section{Electrophysiology in oocytes}

$X$. laevis oocytes were injected with $30 \mathrm{ng}$ eNpHR3.0 cRNA and incubated in medium containing $10 \mu \mathrm{M}$ alltrans-retinal for 2 or 3 days before measurement. Twoelectrode voltage-clamp recordings of photo-currents were made in Ringer's solution with different $\mathrm{pH}$ (110

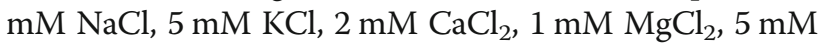
HEPES, pH 7.6; $110 \mathrm{mM} \mathrm{NaCl}, 5 \mathrm{mM} \mathrm{KCl}, 2 \mathrm{mM} \mathrm{CaCl}_{2}$, $1 \mathrm{mM} \mathrm{MgCl} 2,5 \mathrm{mM}$ MES, pH 5.6; and $110 \mathrm{mM} \mathrm{NaCl}, 5$ $\mathrm{mM} \mathrm{KCl}, 2 \mathrm{mM} \mathrm{CaCl} 2,1 \mathrm{mM} \mathrm{MgCl}_{2}, 10 \mathrm{mM}$ CAPSO, $\mathrm{pH}$ 9.6) or in NMG-Asp solution (110 mM NMG, $2 \mathrm{mM}$ $\mathrm{CaCl}_{2}, 1 \mathrm{mM} \mathrm{MgCl}_{2}, 5 \mathrm{mM}$ HEPES, $\mathrm{pH}$ adjusted to 7.6 by aspartate) at a holding potential of $-100,-40$, or $20 \mathrm{mV}$. Solutions with different chloride concentrations were prepared by mixing of Ringer's solution with NMG-Asp solution at different ratios. The recovery from inactivation of eNpHR3.0-mediated currents (Fig. 4f and Fig. 5c, d) was fitted, separately for each cell, by a bi-exponential function of the following form:

$$
\text { recovery }=a 1 \times e^{\frac{-\Delta t}{r 1}}+a 2 \times e^{\frac{-\Delta t}{22}}+c
$$

where $\Delta t$ is the latency of the test pulse onset. The offset cuwas constrained to $100 \%$. The weighted time constant $\tau$ was computed as follows:

$$
\tau_{w}=\tau 1 \times \frac{a 1}{a 1+a 2}+\tau 2 \times \frac{a 2}{a 1+a 2}
$$




\section{Optogenetic stimulation}

For measurements in brain slices, excitation was provided by a 488 -nm diode laser (Cobolt MLD 488) and a 594-nm solid-state laser (Cobolt Mambo), intensitymodulated by an acousto-optic tunable filter (GH18A, Gooch \& Housego) and coupled into a multimode 0.22 NA optical fiber with a core diameter of $200 \mu \mathrm{m}$ (FG200LCC, Thorlabs GmbH). The tip of the fiber was positioned at an axial distance of $\sim 0.5 \mathrm{~mm}$ to the surface of CA1. All power levels indicated were calibrated at the fiber tip, separately for each wavelength (LabMaxTO and OP-2 VIS sensor, Coherent). Photo-stimulation of eNpHR3.0 was performed using either continuous or high-frequency pulse-like $(1 \mathrm{kHz}$, on/off $20 / 80 \%)$ stimulation patterns. The on/off time constant of the acoustooptic tunable filter was $\leq 6 \mu \mathrm{s}$, as quantified using a fast photodiode (PDA100A, Thorlabs).

For oocyte measurements, a 532-nm laser, a 473-nm laser (Changchun New Industries Optoelectronics Tech), a 400-nm LED (ProLight Opto Technology), and a 590nm LED (WINGER) were used as light sources. The light intensities at different wavelengths were measured with a Laser Check optical power meter (Coherent Inc.).

\section{Chemicals}

Chemicals were obtained from Sigma (bicuculline methiodide), Tocris [DL-2-amino-5-phosphonopentanoic acid (APV), 6,7-dinitroquinoxaline-2,3(1H,4H)-dione (DNQX)], and Biotrend [tetrodotoxin (TTX)].

\section{Experimental design and statistical analysis}

Data were analyzed using pClamp 10, WinWCP, Microsoft Excel, and Matlab 2010a/2016a. Statistical analyses were performed using OriginPro 2018, Prism 7 and SPSS Statistics 22/24. All data are reported as mean \pm standard error of the mean (SEM) (Additional file 3). Exact sample sizes for each experiment are given in the "Results" section. The Kolmogorov-Smirnov test was used to test for the normality of data. Parametric testing procedures were applied for normally distributed data; otherwise, non-parametric tests were used. In case of two-sample $t$ tests and unequal group variances, Welch's correction was applied. In case of multiple comparisons, analysis of variance (ANOVA) was used (post hoc tests indicated in the "Results" section). $P$ values (two-tailed tests) $<0.05$ were considered statistically significant.

\section{Supplementary information}

Supplementary information accompanies this paper at https://doi.org/10. 1186/s12915-019-0717-6.

Additional file 1: Figure S1. Co-stimulation at $594 \mathrm{~nm}$ and $488 \mathrm{~nm}$ attenuates the inactivation of eNpHR3.0-mediated currents in somatostatin (SOM) interneurons. A, Sample voltage-clamp recordings from an individual
EYFP+ SOM interneuron in an acute slice obtained from a SOM ${ }^{I R E}$ ${ }^{S c r e}$ :eNpHR3.0-EYFPLL mouse in the presence of TTX $(0.5 \mu \mathrm{M})$. The cell was stimulated for 30 s either continuously at $594 \mathrm{~nm}$ ( $5 \mathrm{~mW}$ at fiber tip) or in an alternating manner at 488/594 nm ( $1 \mathrm{kHz}, 50 / 50 \%$ duty cycle, $5 \mathrm{~mW}$ each at fiber tip). B, Quantification of $I_{\text {peak }}$ and $I_{\text {late. }}$ C, Co-stimulation with blue light substantially reduced inactivation of eNpHR3.0-mediated photo-currents (P3-4). Data are presented as mean \pm SEM. ${ }^{*} P<0.05$, ${ }^{* *} P<0.01,{ }^{* * *} P<$ 0.001.The data set was obtained from cells included in [28].

Additional file 2: Figure S2. Differential effects of eNpHR3.0-mediated chloride loading on network activity in acute hippocampal slices. A, Timecourse of bursts of spontaneous postsynaptic currents (PSCs) at P3-6. PSC burst were virtually absent in the presence of the NKCC1 inhibitor bumetanide $(10 \mu \mathrm{M})$. Subsequent blue-light photo-stimulation (60 s, 488 $\mathrm{nm}, 5 \mathrm{~mW}$ ) of Emx1+ pyramidal cells led to a transient reappearance of PSC bursts. B, Sample voltage-clamp recordings from an individual cell showing PSC bursts (time points as indicated in A). Note that PSC bursts reappear following photo-stimulation (bottom trace). C, Quantification of bursts count per 20-s time bins. D, Sample voltage-clamp recording of spontaneous EPSCs isolated by reversal potential before photostimulation (top), immediately after the offset of photo-stimulation (488 $\mathrm{nm}, 5 \mathrm{~min}, 5 \mathrm{~mW}$; middle) and $\sim 10 \mathrm{~min}$ after photo-stimulation offset (bottom). E, Time-course of EPSC frequency at P11-12 (normalized to the mean of the pre-stimulation period). Note the long-term stability of EPSC frequency after photo-stimulation. Brief interruptions of recordings used to monitor access resistance are not depicted for clarity F, Absolute EPSC frequencies before and after photo-stimulation. Data are presented as mean \pm SEM. n.s. - not significant, ${ }^{* *} P<0.01$.

Additional file 3. Raw data values used for statistical comparisons.

\section{Acknowledgements}

We thank Ina Ingrisch for the technical assistance.

\section{Authors' contributions}

$\mathrm{KK}, \mathrm{KH}, \mathrm{CZ}$, and $\mathrm{GN}$ conceived the study and designed the experiments. $C Z$, SY, and TF performed the experiments. CZ, SY, SG, TF, and KK analyzed the data. All authors contributed to the data interpretation and manuscript preparation. All authors read and approved the final manuscript.

\section{Funding}

This work was supported by the Priority Program 1665 (HO 2156/3-2 to KH, KI 1816/1-2 to KK), the Collaborative Research Center/Transregio 166 (B3 to KH, KK, A3 to GN) and the Research Unit 3004 (KI 1816/5-1 to KK) of the German Research Foundation, and the Interdisciplinary Centre for Clinical Research Jena $(\mathrm{KK}, \mathrm{KH})$.

\section{Availability of data and materials}

All data generated or analyzed during this study are included in this article and its supplementary information.

Ethics approval and consent to participate

Not applicable.

\section{Consent for publication}

Not applicable.

Competing interests

The authors declare that they have no competing interests.

\section{Author details}

${ }^{1}$ Hans-Berger Department of Neurology, Jena University Hospital, Am Klinikum 1, 07747 Jena, Germany. ${ }^{2}$ Present Address: Laboratory of Sensory Processing, Brain Mind Institute, Faculty of Life Sciences, École Polytechnique Fédérale de Lausanne (EPFL), CH-1015 Lausanne, Switzerland. ${ }^{3}$ Institute for Molecular Plant Physiology and Biophysics, Biocenter, \& Institute of Physiology - Neurophysiology, Julius-Maximilians-University of Würzburg, 97070 Würzburg, Germany. ${ }^{4}$ Present Address: Centre for Discovery Brain Sciences, Biomedical Sciences, University of Edinburgh, Edinburgh EH8 9XD, UK. 
Received: 30 September 2019 Accepted: 30 October 2019 Published online: 27 November 2019

\section{References}

1. Klapper SD, Swiersy A, Bamberg E, Busskamp V. Biophysical properties of optogenetic tools and their application for vision restoration approaches. Front Syst Neurosci. 2016;10:74

2. Moser T. Optogenetic stimulation of the auditory pathway for research and future prosthetics. Curr Opin Neurobiol. 2015;34:29-36.

3. Bui AD, Alexander A, Soltesz I. Seizing control: from current treatments to optogenetic interventions in epilepsy. Neuroscientist. 2017;23(1):68-81.

4. Govorunova EG, Sineshchekov OA, Janz R, Liu X, Spudich JL. NEUROSCIENCE. Natural light-gated anion channels: a family of microbial rhodopsins for advanced optogenetics. Science. 2015;349(6248):647-650.

5. Wietek J, Beltramo R, Scanziani M, Hegemann P, Oertner TG, Wiegert JS. An improved chloride-conducting channelrhodopsin for light-induced inhibition of neuronal activity in vivo. Sci Rep. 2015;5:14807.

6. Berndt A, Lee SY, Wietek J, Ramakrishnan C, Steinberg EE, Rashid AJ, Kim H, Park S, Santoro A, Frankland PW, et al. Structural foundations of optogenetics: determinants of channelrhodopsin ion selectivity. Proc Natl Acad Sci U S A. 2016;113(4):822-9.

7. Beck S, Yu-Strzelczyk J, Pauls D, Constantin OM, Gee CE, Ehmann N, Kittel RJ, Nagel G, Gao S. Synthetic light-activated ion channels for optogenetic activation and inhibition. Front Neurosci. 2018;12:643.

8. Bernal Sierra YA, Rost BR, Pofahl M, Fernandes AM, Kopton RA, Moser S, Holtkamp D, Masala N, Beed P, Tukker JJ, et al. Potassium channel-based optogenetic silencing. Nat Commun. 2018;9(1):4611.

9. Siuda ER, McCall JG, Al-Hasani R, Shin G, II Park S, Schmidt MJ, Anderson SL, Planer WJ, Rogers JA, Bruchas MR. Optodynamic simulation of betaadrenergic receptor signalling. Nat Commun. 2015;6:8480.

10. Masseck OA, Spoida K, Dalkara D, Maejima T, Rubelowski JM, Wallhorn L, Deneris ES, Herlitze S. Vertebrate cone opsins enable sustained and highly sensitive rapid control of Gi/o signaling in anxiety circuitry. Neuron. 2014; 81(6):1263-73.

11. Zhang F, Wang LP, Brauner M, Liewald JF, Kay K, Watzke N, Wood PG, Bamberg E, Nagel G, Gottschalk A, et al. Multimodal fast optical interrogation of neural circuitry. Nature. 2007;446(7136):633-9.

12. Gradinaru V, Zhang F, Ramakrishnan C, Mattis J, Prakash R, Diester I, Goshen I, Thompson KR, Deisseroth K. Molecular and cellular approaches for diversifying and extending optogenetics. Cell. 2010;141(1):154-65.

13. Chow BY, Han X, Dobry AS, Qian X, Chuong AS, Li M, Henninger MA, Belfort GM, Lin Y, Monahan PE, et al. High-performance genetically targetable optical neural silencing by light-driven proton pumps. Nature. 2010; 463(7277):98-102.

14. Chuong AS, Miri ML, Busskamp V, Matthews GA, Acker LC, Sorensen AT, Young A, Klapoetke NC, Henninger MA, Kodandaramaiah SB, et al. Noninvasive optical inhibition with a red-shifted microbial rhodopsin. Nat Neurosci. 2014;17(8):1123-9.

15. Wiegert JS, Mahn M, Prigge M, Printz Y, Yizhar O. Silencing neurons: tools, applications, and experimental constraints. Neuron. 2017:95(3):504-29.

16. Szabadics J, Varga C, Molnar G, Olah S, Barzo P, Tamas G. Excitatory effect of GABAergic axo-axonic cells in cortical microcircuits. Science. 2006;311(5758): 233-5.

17. Price GD, Trussell LO. Estimate of the chloride concentration in a central glutamatergic terminal: a gramicidin perforated-patch study on the calyx of Held. J Neurosci. 2006;26(44):11432-6.

18. Mahn M, Prigge M, Ron S, Levy R, Yizhar O. Biophysical constraints of optogenetic inhibition at presynaptic terminals. Nat Neurosci. 2016;19(4): 554-6.

19. Kim JM, Hwa J, Garriga P, Reeves PJ, RajBhandary UL, Khorana HG. Lightdriven activation of beta 2-adrenergic receptor signaling by a chimeric rhodopsin containing the beta 2-adrenergic receptor cytoplasmic loops. Biochemistry. 2005;44(7):2284-92.

20. Airan RD, Thompson KR, Fenno LE, Bernstein H, Deisseroth K. Temporally precise in vivo control of intracellular signalling. Nature. 2009:458(7241):1025-9.

21. Zhang F, Vierock J, Yizhar O, Fenno LE, Tsunoda S, Kianianmomeni A, Prigge M, Berndt A, Cushman J, Polle J, et al. The microbial opsin family of optogenetic tools. Cell. 2011;147(7):1446-57.

22. Han X, Boyden ES. Multiple-color optical activation, silencing, and desynchronization of neural activity, with single-spike temporal resolution. PLoS One. 2007;2(3):e299.
23. Tonnesen J, Sorensen AT, Deisseroth K, Lundberg C, Kokaia M. Optogenetic control of epileptiform activity. Proc Natl Acad Sci U S A. 2009;106(29):12162-7.

24. Mattis J, Tye KM, Ferenczi EA, Ramakrishnan C, O'Shea DJ, Prakash R, Gunaydin LA, Hyun M, Fenno LE, Gradinaru V, et al. Principles for applying optogenetic tools derived from direct comparative analysis of microbial opsins. Nat Methods. 2011:9(2):159-72.

25. Alfonsa H, Merricks EM, Codadu NK, Cunningham MO, Deisseroth K, Racca C, Trevelyan AJ. The contribution of raised intraneuronal chloride to epileptic network activity. J Neurosci. 2015;35(20):7715-26.

26. Bamberg E, Tittor J, Oesterhelt D. Light-driven proton or chloride pumping by halorhodopsin. Proc Natl Acad Sci U S A. 1993;90(2):639-43.

27. Kummer M, Kirmse K, Witte OW, Holthoff K. Reliable in vivo identification of both GABAergic and glutamatergic neurons using Emx1-Cre driven fluorescent reporter expression. Cell Calcium. 2012;52(2):182-9.

28. Flossmann T, Kaas T, Rahmati V, Kiebel SJ, Witte OW, Holthoff K, Kirmse K. Somatostatin interneurons promote neuronal synchrony in the neonatal hippocampus. Cell Rep. 2019;26(12):3173-82.

29. Kanada S, Takeguchi Y, Murakami M, Ihara K, Kouyama T. Crystal structures of an O-like blue form and an anion-free yellow form of pharaonis halorhodopsin. J Mol Biol. 2011;413(1):162-76.

30. Raimondo JV, Kay L, Ellender TJ, Akerman CJ. Optogenetic silencing strategies differ in their effects on inhibitory synaptic transmission. Nat Neurosci. 2012;15(8):1102-4.

31. Zhu L, Polley N, Mathews GC, Delpire E. NKCC1 and KCC2 prevent hyperexcitability in the mouse hippocampus. Epilepsy Res. 2008;79(2-3):201-12.

32. Ben-Ari Y, Cherubini E, Corradetti R, Gaiarsa JL. Giant synaptic potentials in immature rat CA3 hippocampal neurones. J Physiol. 1989;416:303-25.

33. Dzhala VI, Talos DM, Sdrulla DA, Brumback AC, Mathews GC, Benke TA,

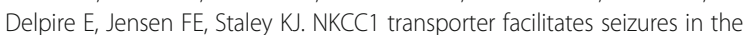
developing brain. Nat Med. 2005;11(11):1205-13.

34. Spoljaric A, Seja P, Spoljaric I, Virtanen MA, Lindfors J, Uvarov P, Summanen $M$, Crow AK, Hsueh B, Puskarjov M, et al. Vasopressin excites interneurons to suppress hippocampal network activity across a broad span of brain maturity at birth. Proc Natl Acad Sci U S A. 2017:114(50):E10819-28.

35. Hegemann $P$, Oesterbelt D, Steiner M. The photocycle of the chloride pump halorhodopsin. I: azide-catalyzed deprotonation of the chromophore is a side reaction of photocycle intermediates inactivating the pump. EMBO J. 1985;4(9):2347-50.

36. Lanyi JK. Mechanism of base-catalyzed Schiff base deprotonation in halorhodopsin. Biochemistry. 1986;25(21):6706-11.

37. Steiner $M$, Oesterhelt $D$. Isolation and properties of the native chromoprotein halorhodopsin. EMBO J. 1983;2(8):1379-85.

38. Kouyama T, Kanada S, Takeguchi Y, Narusawa A, Murakami M, Ihara K. Crystal structure of the light-driven chloride pump halorhodopsin from Natronomonas pharaonis. J Mol Biol. 2010;396(3):564-79.

39. Varo G, Brown LS, Sasaki J, Kandori H, Maeda A, Needleman R, Lanyi JK. Light-driven chloride ion transport by halorhodopsin from Natronobacterium pharaonis. 1. The photochemical cycle. Biochemistry. 1995:34(44):14490-9.

40. Chizhov I, Engelhard M. Temperature and halide dependence of the photocycle of halorhodopsin from Natronobacterium pharaonis. Biophys J. 2001;81(3):1600-12.

41. Mevorat-Kaplan K, Brumfeld V, Engelhard M, Sheves M. Effect of anions on the photocycle of halorhodopsin. Substitution of chloride with formate anion. Biochemistry. 2005;44(43):14231-7.

42. Oesterhelt D, Hess B. Reversible photolysis of the purple complex in the purple membrane of Halobacterium halobium. Eur J Biochem. 1973;37(2): $316-26$

43. Ormos $P$, Dancshazy $Z$, Karvaly $B$. Mechanism of generation and regulation of photopotential by bacteriorhodopsin in bimolecular lipid membrane. Biochim Biophys Acta. 1978;503(2):304-15.

44. Nagel G, Mockel B, Buldt G, Bamberg E. Functional expression of bacteriorhodopsin in oocytes allows direct measurement of voltage dependence of light induced H+ pumping. FEBS Lett. 1995;377(2):263-6.

45. Kouyama T, Kawaguchi H, Nakanishi T, Kubo H, Murakami M. Crystal structures of the $L 1, L 2, N$, and $O$ states of pharaonis halorhodopsin Biophys J. 2015;108(11):2680-90.

46. Bedbrook CN, Yang KK, Robinson JE, Gradinaru V, Arnold FH. Machine learning-guided channelrhodopsin engineering enables minimally-invasive optogenetics. Nat Methods. 2019. Epub ahead of print. https://doi.org/10. 1038/s41592-019-0583-8. 
47. Arrenberg AB, Del Bene F, Baier H. Optical control of zebrafish behavior with halorhodopsin. Proc Natl Acad Sci U S A. 2009;106(42):17968-73.

48. Owen SF, Liu MH, Kreitzer AC. Thermal constraints on in vivo optogenetic manipulations. Nat Neurosci. 2019;22(7):1061-5.

49. Gorski JA, Talley T, Qiu M, Puelles L, Rubenstein JL, Jones KR. Cortical excitatory neurons and glia, but not GABAergic neurons, are produced in the Emx1-expressing lineage. J Neurosci. 2002;22(15):6309-14.

50. Madisen L, Mao T, Koch H, Zhuo JM, Berenyi A, Fujisawa S, Hsu YW, Garcia AJ 3rd, Gu X, Zanella S, et al. A toolbox of Cre-dependent optogenetic transgenic mice for light-induced activation and silencing. Nat Neurosci. 2012;15(5):793-802.

51. Taniguchi H, He M, Wu P, Kim S, Paik R, Sugino K, Kvitsiani D, Fu Y, Lu J, Lin $Y$, et al. A resource of Cre driver lines for genetic targeting of GABAergic neurons in cerebral cortex. Neuron. 2011;71(6):995-1013.

\section{Publisher's Note}

Springer Nature remains neutral with regard to jurisdictional claims in published maps and institutional affiliations.

Ready to submit your research? Choose BMC and benefit from:

- fast, convenient online submission

- thorough peer review by experienced researchers in your field

- rapid publication on acceptance

- support for research data, including large and complex data types

- gold Open Access which fosters wider collaboration and increased citations

- maximum visibility for your research: over $100 \mathrm{M}$ website views per year

At $\mathrm{BMC}$, research is always in progress.

Learn more biomedcentral.com/submissions 